\title{
Horizontal acquisition of hydrogen conversion ability and other habitat adaptations in the Hydrogenovibrio strains SP-41 and XCL-2
}

Giorgio Gonnella ${ }^{1 *}$, Nicole Adam²,3 and Mirjam Perner ${ }^{2,3^{*}}$

\begin{abstract}
Background: Obligate sulfur oxidizing chemolithoauthotrophic strains of Hydrogenovibrio crunogenus have been isolated from multiple hydrothermal vent associated habitats. However, a hydrogenase gene cluster (encoding the hydrogen converting enzyme and its maturation/assembly machinery) detected on the first sequenced $H$. crunogenus strain (XCL-2) suggested that hydrogen conversion may also play a role in this organism. Yet, numerous experiments have underlined XCL-2's inability to consume hydrogen under the tested conditions. A recent study showed that the closely related strain SP-41 contains a homolog of the XCL-2 hydrogenase (a group $1 \mathrm{~b}$ [NiFe]-hydrogenase), but that it can indeed use hydrogen. Hence, the question remained unresolved, why SP-41 is capable of using hydrogen, while $\mathrm{XCL}-2$ is not.

Results: Here, we present the genome sequence of the SP-41 strain and compare it to that of the XCL-2 strain. We show that the chromosome of SP-41 codes for a further hydrogenase gene cluster, including two additional hydrogenases: the first appears to be a group $1 \mathrm{~d}$ periplasmic membrane-anchored hydrogenase, and the second a group $2 \mathrm{~b}$ sensory hydrogenase. The region where these genes are located was likely acquired horizontally and exhibits similarity to other Hydrogenovibrio species (H. thermophilus MA2-6 and H. marinus MH-110 ${ }^{T}$ ) and other hydrogen oxidizing Proteobacteria (Cupriavidus necator $\mathrm{H} 16$ and Ghiorsea bivora TAG-1 ${ }^{\top}$ ). The genomes of XCL-2 and SP-41 show a strong conservation in gene order. However, several short genomic regions are not contained in the genome of the other strain. These exclusive regions are often associated with signs of DNA mobility, such as genes coding for transposases. They code for transport systems and/or extend the metabolic potential of the strains.

Conclusions: Our results suggest that horizontal gene transfer plays an important role in shaping the genomes of these strains, as a likely mechanism for habitat adaptation, including, but not limited to the transfer of the hydrogen conversion ability.
\end{abstract}

Keywords: Hydrogenase, Hydrogenovibrio, Horizontal gene transfer, Hydrothermal vents, Habitat adaptation, Bacterial genome, Genome comparison

*Correspondence: gonnella@zbh.uni-hamburg.de; mperner@geomar.de

'Universität Hamburg, MIN-Fakultät, ZBH - Center for Bioinformatics,

Bundesstraße 43, 20146 Hamburg, Germany

${ }^{2}$ GEOMAR Helmholtz Center for Ocean Research Kiel, Geomicrobiology,

Wischhofstr. 1-3, 24148 Kiel, Germany

Full list of author information is available at the end of the article

(c) The Author(s). 2019 Open Access This article is distributed under the terms of the Creative Commons Attribution 4.0 International License (http://creativecommons.org/licenses/by/4.0/), which permits unrestricted use, distribution, and reproduction in any medium, provided you give appropriate credit to the original author(s) and the source, provide a link to the Creative Commons license, and indicate if changes were made. The Creative Commons Public Domain Dedication waiver 


\section{Background}

Hydrogenovibrio crunogenus (recently reclassified by [1]) was originally isolated from a deep-sea hydrothermal vent and described as the sulfur-oxidizing Thiomicrospira crunogena, belonging to the Gammaproteobacteria [2]. Since then numerous strains, tentatively assigned by phylogenetic analyses to this species, have been isolated from ubiquitous deep-sea hydrothermal vents: e.g. TH- $55^{T}$ [2] from the Eastern Pacific Rise; L-12 [3] and XCL2 [4] from the Galapagos Rift, Eastern Pacific; HY-62 [5] from the North Fiji Basin, Western Pacific; 37-SI2 [6] from the Yonaguni Knoll IV field in the Western Pacific; MA-3 [7] from the Trans-Altantic Geotraverse. A close relative of $H$. crunogenus XCL-2, according to a $16 \mathrm{~S}$ rRNA gene-based phylogenetic analysis [8], is strain SP-41, isolated from low-temperature fluids, collected near the Sisters Peak chimney, Mid-Atlantic Ridge [9].

For many years, members of the Thiomicrospira lineage, now reclassified into Hydrogenovibrio, Thiomicrospira and Thiomicrorhabdus [1], were considered to be indicators for sulfur cycling, as they were known to oxidize reduced sulfur compounds, such as hydrogen sulfide, thiosulfate and tetrathionate ([10], e.g.). The only species among this clade known to oxidize hydrogen was Hydrogenovibrio marinus [11, 12], while other phylogenetically closely related organisms remained recalcitrant for many years towards cultivation with hydrogen ([13], and references therein). It was not until the genome of XCL-2 was sequenced, that first indications for alternative energy sources were suggested, based on the hydrogenase genes found on the chromosome [14]. More recently the ability throughout this group to oxidize hydrogen was demonstrated for several strains $[8,15]$ explaining why some of these organisms are found in relatively sulfide low but hydrogen rich vent systems, such as Lost City, where metagenomic sequences highly similar to the XCL-2 genome were observed [16]. Intriguingly, although the genome of XCL-2 includes a complete set of genes for the assembly and maturation of a [NiFe]-hydrogenase (EC 1.12.1.2) [14], the strain is unable to grow on hydrogen, under all tested conditions [8]. For some of the H. crunogenus strains (SP$41, \mathrm{TH}-55^{T}$ ) capable of oxidizing hydrogen, it has been shown that this ability depends on the concentrations of $\mathrm{Ni}$ and $\mathrm{Fe}$ in the medium (strains SP-41 and TH- $55^{T}$ [13]), but in case of XCL-2 this supplementation made no difference with respect to its hydrogen consumption ability [8].

Hansen and Perner [8] cloned and characterized the [NiFe]-hydrogenase large subunits from several Hydrogenovibrio and Thiomicrospira strains (MA2-3, L12, JB-B2, TH- $55^{T}$ ) and compared the gene order of the hydrogenase gene cluster in XCL-2 to that of related organisms. Their analysis lead to several hypotheses about why XCL-2 cannot but other phylogenetically closely related strains can indeed utilize hydrogen. Important features missing from XCL-2 could be a membraneanchoring cytochrome $b$ subunit, a Tat-signal and proper [Fe-S]-cluster binding sites in the small subunit. However, as, until now, no genome sequence has been available for hydrogen consuming strains assigned or closely related to $H$. crunogenus, it has not been possible to verify these hypotheses. Nevertheless, the genomes of several other members of the genera Hydrogenovibrio, Thiomicrospira and Thiomicrorhabdus have been sequenced [17-21]. A recent comparative genomic analysis focused on 18 strains of these genera [21] and identified several genomic features responsible for adaptations to habitat variability of these organisms, likely explaining their cosmopolitan distribution. Horizontal acquisition was suggested for the hydrogenase genes present in some strains of $H$. thermophilus and $H$. marinus, due to their uneven distribution throughout the members of these genera, and the presence of phage genes in juxtaposition to the hydrogenase gene cluster. However, the differences throughout $H$. crunogenus strains remained puzzling, as a hydrogenase gene cluster is contained also on the XCL-2 genome, and the study does not include other strains of H. crunogenus.

We present here the complete genome sequence of the hydrogen consuming strain SP-41, and compare it to the genome of XCL-2. Our analysis shows that additional, likely horizontally acquired, genetic material in each of the strains, reflect probable adaptations of these organisms to their habitats. This includes an additional hydrogenase gene cluster in SP-41, which could explain the different hydrogen consumption abilities of the two strains.

\section{Results and Discussion}

\section{Sequencing and annotation of the SP-41 genome}

The genome assembly of the isolated SP-41 was obtained using the Pacific Biosciences platform. The reads (total length of $1.24 \mathrm{Gbp}, 503 \mathrm{X}$ coverage) were assembled into a single $2.47 \mathrm{Mbp}$ long contig. Illumina sequences previously obtained from the enrichment culture from which SP-41 was isolated were mapped to the assembly and used for 192 corrections (mostly of single nucleotides).

The final assembly is 2'453'259 bp long. The genome includes 9 rRNA genes (3 copies of 23S, 16S and 5S), 44 tRNA genes (for all canonical amino acids), a tmRNA gene and 2293 protein coding genes (Fig. 1). $87.3 \%$ of the protein products had a specific annotation (i.e. not "hypothetical protein") and $37.5 \%$ were assigned an EC number by Prokka [22]. COG annotations by CD-search [23] were assigned to $64.0 \%$ of the proteins (Additional file 1), and $\mathrm{KO}$ annotations by Blastkoala [24] to $64.2 \%$ of the proteins (Additional file 2). 


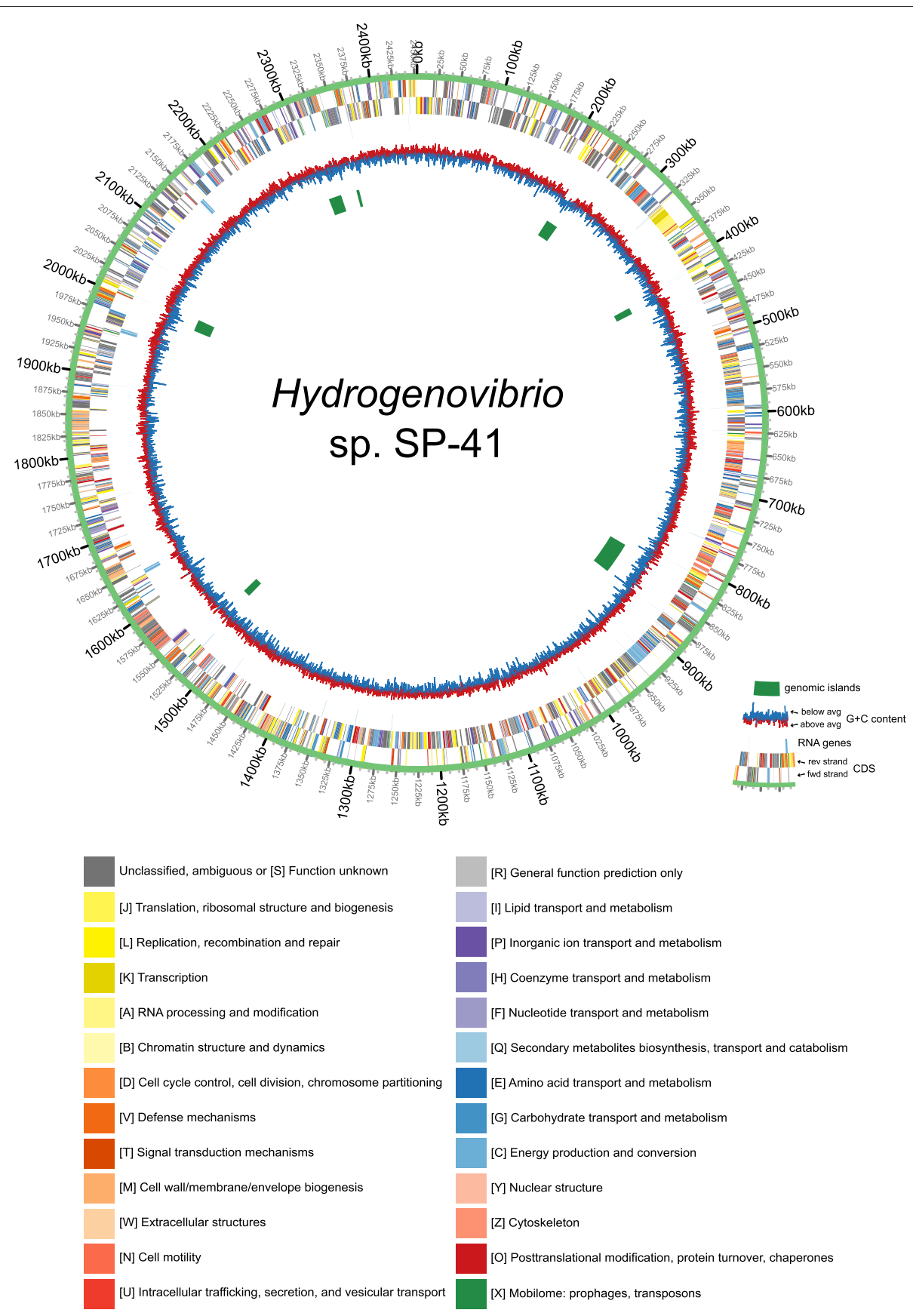

Fig. 1 Circos plot of the genome of Hydrogenovibrio sp. SP-41. From the outside to theinside, the plot contains the following tracks: CDS (plus strand); CDS (minus strand); RNA genes (both strands); G+C content; genomic islands. The CDS are colored according to the COG annotation (functional categories, see legend on the right)

\section{Phylogenetic relation to other strains}

Analysis of the average nucleotide identity (ANI), shows that the strain most closely related to SP-41, for which a genome sequence is available, is XCL-2 (Additional file 3). Most proteins encoded by the SP-41 genome (2019 or $88.1 \%$ ) have a homolog in XCL-2, in most cases (1986) encoded by a gene in the same position of the alignment of the two genomes (Additional file 4). In both strains, a similar proportion of proteins have no ortholog in the other strain $(11.9 \%$ of proteins of SP-41; $11.4 \%$ XCL-2). In SP-41, these exclusive proteins are more often uncharacterized: $28.8 \%$ 
of them are hypothetical proteins in SP-41, $10.6 \%$ in XCL-2.

The relatedness of SP- 41 and XCL- 2 was already suggested by a previous partial sequencing of the $16 \mathrm{~S}$ rRNA gene of SP-41 (Genbank KJ573628), in which only 3 differences were found compared to the 16S rRNA gene of XCL-2 (which itself has 3 identical 16S copies) [9]. The $16 \mathrm{~S}$ rRNA gene sequences obtained from the genome sequencing of SP-41 confirm one of the 3 differences, located in the $\mathrm{V} 7$ hypervariable region, present in all three $16 \mathrm{~S}$ rRNA gene copies of SP-41 (Additional file 5). The further two differences previously observed are not confirmed by the genome sequencing (they are located in the forward sequencing primer region and were likely a sequencing artefact). However, the genome sequence of SP-41 also highlighted the intragenomic heterogeneity of its 16S rRNA genes. Through the genome sequencing, it became clear that the previously published $16 \mathrm{~S}$ rRNA gene sequence of SP-41 actually represented a consensus sequence, as each of the copies have additional differences, compared to XCL-2, not present in the other two copies (and not present in the previously published sequence). The differences in single copies were masked in the sequencing by the other two copies and lead to wrong base callings (Additional file 6). These are located in the $\mathrm{V} 1$ region (1 difference, 1st 16S rRNA gene copy) and V2 region (4 differences, 2nd 16S rRNA copy; 2 differences, 3rd 16S rRNA gene copy). The high level of $16 \mathrm{~S}$ rRNA gene identity between SP-41 and XCL-2 is thus confirmed, ranging from $99.7 \%$ to $99.9 \%$ depending on which SP-41 $16 \mathrm{~S}$ rRNA gene copy is considered.

Phylogeny reconstruction based on the $16 \mathrm{~S}$ rRNA genes [8] assigned several strains to the $H$. crunogenus species: TH-55 ${ }^{T}$, SP-41, XCL-2, L-12, EPR75, 37-SI-2, MA-3, HY62 . However, the comparison of the genome sequences of SP-41 and XCL-2 shows that these two strains belong to two different species, as their ANI of $87.7 \%$ is significantly below the $95 \%$ threshold suggested for species definition [25]. Despite this, the two strains are the closest relative of each other for which a genome sequence is available (Additional file 3). For the other strains mentioned before, only the sequences of the $16 \mathrm{~S}$ rRNA gene and in some cases of the hynL gene are available [8]. Without further genome sequences it is thus not possible to accurately reconstruct the phylogeny of the lineage and, in particular, to understand, if the other strains previously assigned to $H$. crunogenus should be assigned to the same species as SP-41.

\section{Genomic structure and plasticity}

The genome of SP-41 is slightly larger (25.5 kbp or $1.0 \%$ more) than that of XCL-2. The dot plot of their alignment of the genome sequence of SP-41 to that of XCL-2 (Fig. 2) shows that most regions of the two genomes are

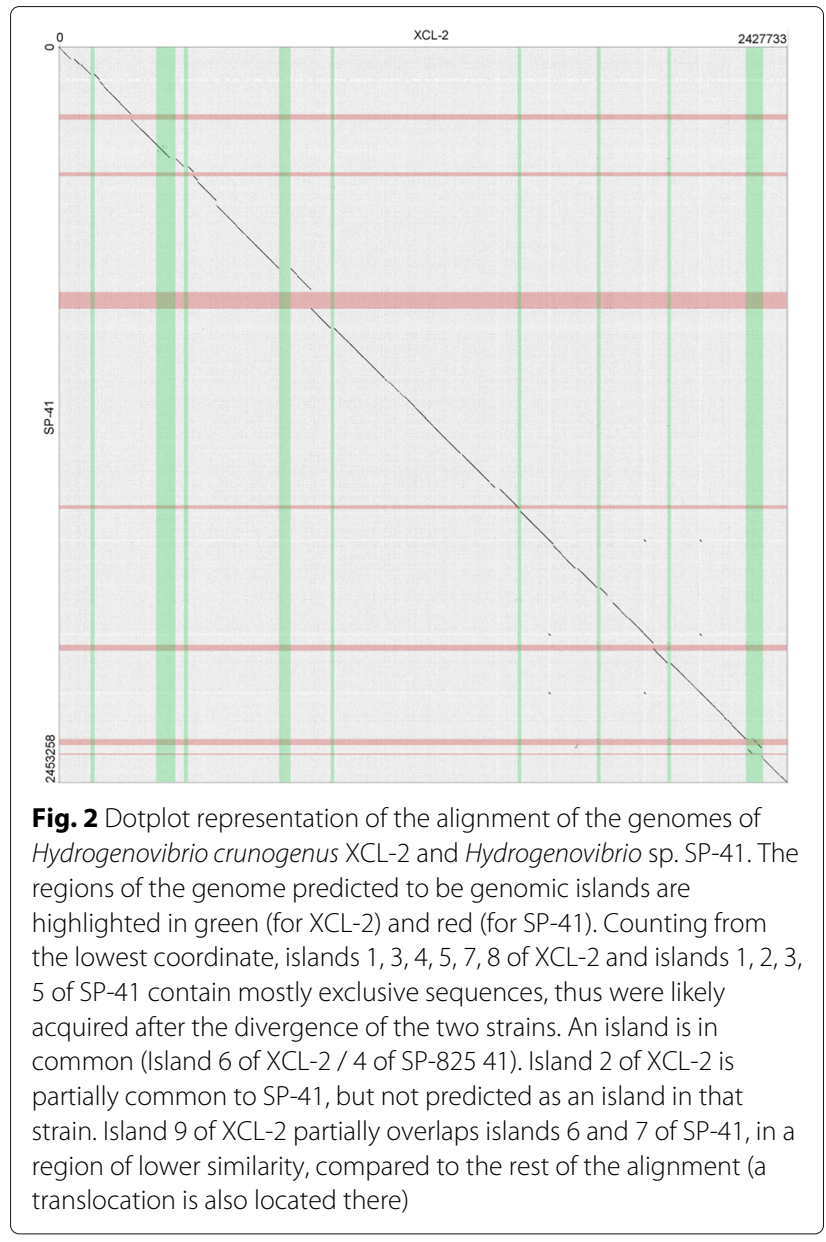

homologous and collinear (in total $2.17 \mathrm{Mbp}, 88.6 \%$ of the SP-41 genome; $89.7 \% \mathrm{XCL}-2)$. The remaining parts of the alignment (Additional file 7) include (a) 61 exclusive regions, where one genome contains a sequence with at least one annotated feature (36 regions in SP-41 and 25 in XCL-2), and the other genome contains either no sequence or a non-homologous sequence with no features; (b) 12 divergent regions, non-homologous and containing at least one feature in both genomes; (c) a single translocation, i.e. homologous region of $12.1 \mathrm{kbp}$ which is located $50 \mathrm{kbp}$ ahead in the SP-41 sequence, with respect to the rest of the aligned sequences.

The alignment does not reveal if the additional sequences found in exclusive and divergent regions represent sequences lost in the other strain, compared to the last common ancestor, or acquired by horizontal transfer. Thus, we analyzed the two genomes using IslandViewer [26] to identify genomic islands. In total, 7 islands were found in SP-41 (Additional file 8), between $4.5 \mathrm{kbp}$ and $51.6 \mathrm{kbp}$ in length, coding for a total of 148 protein-coding genes (Additional file 9). For comparison, XCL-2 contains 
9 islands, between $7.6 \mathrm{kbp}$ and $64.8 \mathrm{kbp}$, with a total of 377 protein-coding genes (Additional file 10).

In the dot plot in Fig. 2, we highlighted the coordinate ranges of the islands in SP-41 (green) and XCL-2 (red), to allow a visual identification of the overlap of islands of the two genomes and of the islands with exclusive regions. The results show that only part of the islands overlap with exclusive regions of the two genomes: 13 exclusive regions in SP-41 and 12 regions in XCL-2. This appears to be more consistent to a loss of sequences after strain divergence for the remaining exclusive regions.

All genomic island prediction software is based on heuristics, which might fail to find the exact island boundaries or even miss entire islands in some cases. The island annotation by IslandViewer is based on the combination of two programs: IslandPath-DIMOB which looks for dinucleotide biases in a region of at least 8 consecutive genes, including a mobility gene [27]; Islander which looks for regions flanked by a tRNA gene or a tRNA gene fragment and containing an integrase gene. The limitations in predicting genomic islands are shown by the second island of XCL-2, which is largely homologous to SP-41, where, however, no island is predicted in the region. Furthermore, proteins related to transposition are present in other 5 of SP-41 exclusive regions not overlapping predicted islands (while in XCL-2 they are present only in predicted genomic islands), indicating possible further islands not recognized by the prediction software.

As discussed in [14], XCL-2 contains a prophage sequence, which is not present in SP-41, and represents the largest exclusive region of XCL-2 (38.7 kbp) in the alignment to SP-41. However, in general, SP41 shows a trend towards more genome plasticity: It contains more exclusive regions (36 vs 25), although of slightly smaller average size (5.6 vs $6.4 \mathrm{kbp}$ ) than the exclusive regions of XCL-2. Furthermore, 30 SP41 but only 3 XCL- 2 proteins were annotated with transposase/putative transposase KO (K07483;K07497) and/or COGs (COG2801;COG2963;COG3328). In environments associated with hydrothermal venting, a high prevalence of transposases has been previously observed in the biofilm coating the carbonate chimneys of Lost City [28]. There it has been hypothesized to serve as a generator of phenotypic diversity as counterpart to the low organismal diversity of the biofilm community, and possibly contributing to its overall fitness. Both strains XCL-2 and SP-41 were isolated from hydrothermally influenced samples. Thus it remains unclear, which other factors explain the presence and abundance of transposases in one, but not in the other strain.

A $6.0 \mathrm{kbp}$ exclusive region of SP-41 contains a CRISPR array, with 22 repeat units, and the associated proteins Cas1, Cas2 and Cas9. CRISPRs are thought to confer immunity towards invading DNA, such as plasmids and viruses, matching the spacers' sequences [29]. This could be more useful in habitats where DNA mobility is more common. To understand if the presence of a CRISPR could be correlated to the abundance of transposases observed in SP-41, we counted the number of transposases and CRISPRs in a group of autotrophic Proteobacteria genomes previously analysed by [21]. We found that, in these organisms, the average number of transposases is significantly higher (p-value 0.02) in genomes with annotated CRISPRs (27.3 transposases in average) than in those where no CRISPR is present (14.6 transposases in average) (Additional file 11). However, e.g. within the Thiomicrospira/Hydrogenovibrio/Thiomicrorhabdus lineage this is not always the case. Hydrogenovibrio sp. Milos-T1 and Thiomicrorhabdus sp. Milos-T2 have a high number of transposases [21], but a CRISPR was annotated only in Milos-T1. Other members of the lineage containing a CRISPR (Hydrogenovibrio halophilus DSM $15072^{T}$, Hydrogenovibrio marinus $\mathrm{MH}-110^{T}$, Hydrogenovibrio sp. MA2-6, Thiomicrorhabdus sp. Kp2, Thiomicrospira aerophila $\mathrm{AL}^{T}{ }^{T}$, Thiomicrospira microaerophila ASL8-2 ${ }^{T}$ ) do not generally show a high number of transposases.

\section{Hydrogenase gene clusters}

The hydrogenase gene cluster (encoding the structural hydrogenases, catalyzing $\mathrm{H}_{2} \leftrightarrow 2 H^{+}+2 e^{-}$as well as accessory, assembly and maturation proteins) of XCL-2 is also found in SP-41 (genes GHNINEIG_02156 to GHNINEIG_02165). For ease of reading we name it hydrogenase gene cluster I. The hydrogenase belongs to group 1b [30]. The gene for the large subunit had been previously cloned and characterized [8]. The small subunit has the same unusually large size, as in XCL-2 (813 aa). The entire cluster is present also in SP-41, with the same gene order as in XCL-2.

Besides the XCL-2 resembling hydrogenase gene cluster, a further hydrogenase gene cluster is located on the SP-41 genome (here named hydrogenase gene cluster II). It is part of the largest exclusive region of the SP-41 genome (relative to XCL-2) with $62.6 \mathrm{kbp}$ (starting at position 808620 ). In total, this exclusive region contains 63 protein-coding genes. Up- and downstream of this region are genes involved in DNA mobilization and modification. A horizontal acquisition of this region is supported by the genomic island prediction, which covers a large part of the area (the last $50.4 \mathrm{kbp}$ ). The hydrogenase gene cluster and some related genes (described below) are contained in the central part of the region (27 genes, from gene GHNINEIG_00794 to gene GHNINEIG_00820). 
The first of the two hydrogenases from the hydrogenase gene cluster II is encoded by genes GHNINEIG_00797 (large subunit) and GHNINEIG_00798 (small subunit). The small subunit contains the Tat motif RRXFXK important for the translocation to the periplasm [31]. This motif is absent in the other two small subunits from the hydrogenase gene cluster I encoded on both SP-41 and XCL-2 genomes. Furthermore, the presence of a cytochrome $\mathrm{b}$ subunit gene (gene GHNINEIG_00796) on the hydrogenase gene cluster II suggests anchoring of the hydrogenase to the membrane [32]. In contrast, this gene is not present in hydrogenase gene cluster I and in its homolog in XCL-2. SP-41 hydrogenase activity was shown to be localized in the membrane and not in the soluble fraction [9]. The lack of the Tat motif and Cytochrome b subunit was postulated to be a possible reason for the hydrogenase inactivity, under the tested conditions, of the XCL-2 hydrogenase [8]. Their presence here could explain why SP-41 is able to consume hydrogen, while $\mathrm{XCL}-2$ is not.

Sequence motifs of the hydrogenases encoded by genes GHNINEIG_00797 and GHNINEIG_00798 resemble hydrogenases assigned to group 1d [30]. In particular, the large subunit (gene GHNINEIG_00797) contains L1 (VERICGVCTGCH) and L2 (SFDPCLACSTH) motifs compatible with the group 1d classification [30]). Interestingly, the L3 (HDHIVHFYHLHALD) and L4 motifs (GTVAAPRGALAH) are the canonical motifs, i.e. those not found in the XCL-2 hydrogenase large subunit and its ortholog in SP-41. The small subunit (gene GHNINEIG_00798) contains proximal and distal cluster binding motifs typical of group $1 \mathrm{~d}$, while the 5 th position of the medial binding motif (FPIQAGHGCIGCS) contains an Alanine instead of a Serine of the described motif for group 1d (xPIXSGHXCxGCx) and is compatible to group $1 f$.

The second hydrogenase in the hydrogenase gene cluster II is encoded by genes GHNINEIG_00818 (large subunit) and GHNINEIG_00819 (small subunit). Its small subunit does not contain a Tat-motif. Its medial and distal cluster binding motifs are compatible with group $2 \mathrm{~b}$, while the proximal cluster binding motif contains a Serine instead of Glycine at its third position, when compared to the motif described for group $2 b$ $(x C G G C x--x C x x x G G--x C P)$. The large subunit contains L1 (APRICGICSVSQ) and L2 (SFDPCMVCTVH) motifs compatible with this group assignment. This suggests a sensory function for this hydrogenase [30]. The following gene (GHNINEIG_00820) is an homolog of the Escherichia coli $\mathrm{K} 12$ zraS/hydH gene. This is a sensory protein kinase [33], originally described as regulating the labile hydrogenase activity in E. coli $\mathrm{K} 12$ [34] and is also homologous to the HoxJ component of the hydrogensensing system of Cupriavidus necator (formerly Alcaligenes eutrophus) [35].

\section{Function of the hydrogenase clusters}

In order to test the expression of the two group 1 [NiFe]hydrogenases (group 1b, encoded by hydrogenase cluster I, and group 1d, encoded by hydrogenase cluster II), we performed qRT-PCR experiments with RNA extracts of SP-41, grown with an atmosphere of $\mathrm{H}_{2}: \mathrm{CO}_{2}: \mathrm{O}_{2}$ : $\mathrm{He}(2: 20: 1: 78 \%(v / v))$. Both cluster I and cluster II [NiFe]-hydrogenases are expressed in SP-41 under the tested cultivation conditions, i.e. with (MJ-T medium) and without (MJ medium) thiosulfate addition (Fig. 3). For both hydrogenases the highest expression levels are observed after $24 \mathrm{~h}$ and if hydrogen is the only available electron donor. If thiosulfate is available in the medium, the relative expression of both hydrogenase genes is significantly lower. In contrast to the MJ incubation, in the thiosulfate supplemented MJ-T medium the highest expression levels of both hydrogenases is observed after $8 \mathrm{~h}$ incubations. For the cluster I hydrogenase, this was already shown in [9]. This effect is most obvious for the cluster II hydrogenase, which altogether exhibits considerably lower expression levels than the cluster I hydrogenase in the MJ-T incubations.

It was previously observed that membrane fractions of hydrogen-oxidizing Hydrogenovibrio strains containing a group 1 b hydrogenase (e.g. SP-41) display a higher hydrogenase activity rate than those containing a group $1 \mathrm{~d}$ hydrogenase (MA2-6, MH-110) [8]. However, the presence of the group $1 b$ hydrogenase alone (in XCL-2) does not confer the ability to oxidize hydrogen under all tested conditions. Also the presence of a group 1d hydrogenase alone does not necessarily explain all aspects of the observed hydrogenase activity. E.g. although both strains contain a group $1 \mathrm{~d}$ hydrogenase, the hydrogen affinity of the hydrogenases of MA2-6 and SP-41 appears to be different: MA2- 6 consumes initially more $\mathrm{H}_{2}$, but its activity ends at higher $\mathrm{H}_{2}$ concentrations [8].

The degree of sequence conservation, and gene expression in SP-41, suggest that also cluster I genes do actually encode a structural hydrogenase [8]. As both hydrogenases are expressed simultaneously during the observed hydrogen consumption activity, it is possible that some components of hydrogenase gene cluster II, missing or not functional in cluster I, affect the other cluster. As no hydrogenase activity was detected in soluble fractions [8], this would require anchoring of the hydrogenase of cluster I to the membrane by components of cluster II, e.g. by its cytochrome b subunit. Some chaperons and maturation proteins of cluster II might as well affect the cluster I hydrogenase. Also, the group $2 \mathrm{~b}$ sensory hydrogenase might regulate the expression of the cluster I hydrogenase. A similar regulation mechanism appears to affect both hydrogenases, as the expression levels of both hydrogenases correlate well (Fig. 3). Further experiments will be necessary to test these hypotheses. 
a Group 1b [NiFe]-hydrogenase (gene cluster I)

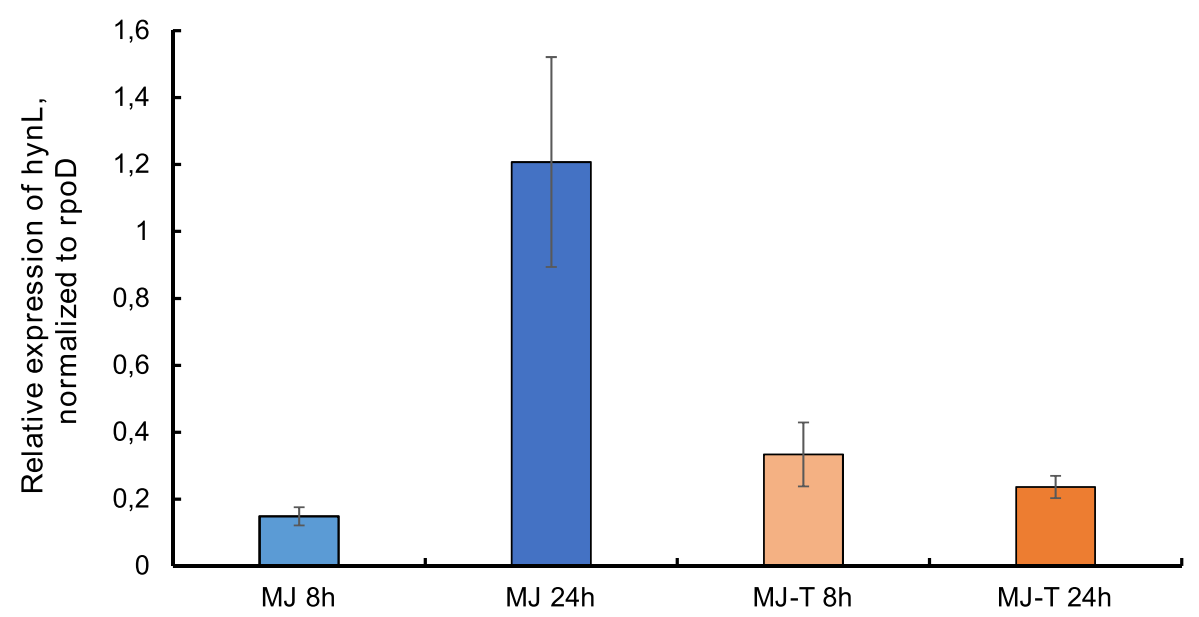

b Group 1d [NiFe]-hydrogenase (gene cluster II)

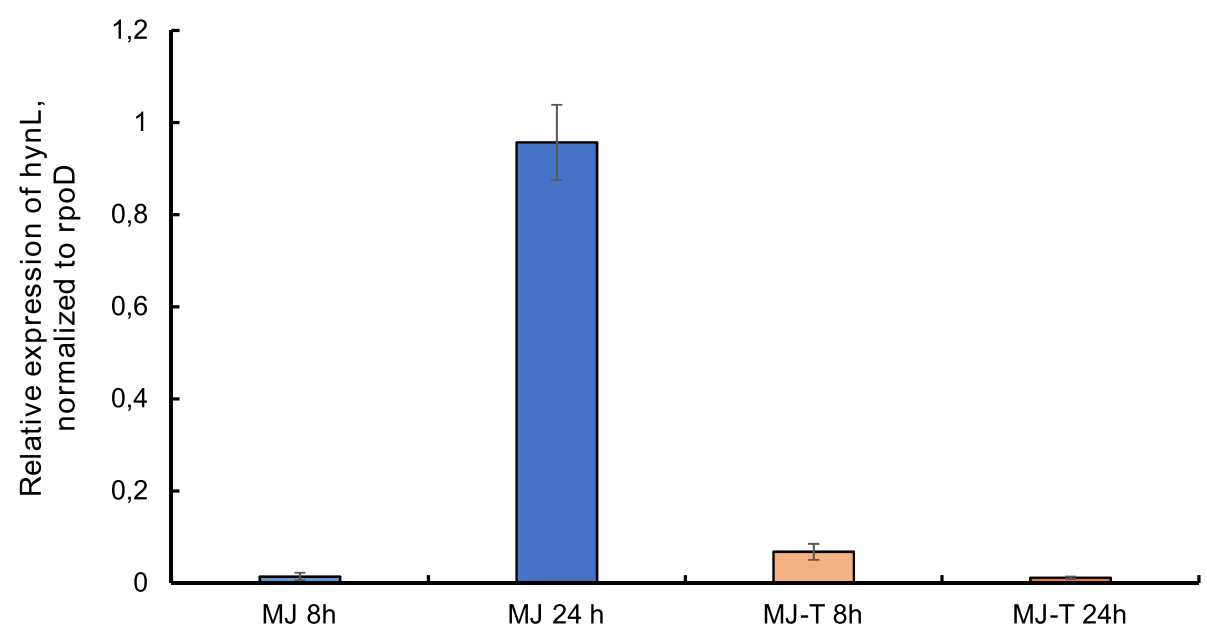

Fig. 3 Expression of SP-41's hydrogenase genes under different cultivation conditions. Relative expression of the hynL genes for the large subunit group 1 [NiFe]-hydrogenases in hydrogenase gene cluster | $\mathbf{a}$ and cluster || $\mathbf{b}$, normalized to the housekeeping gene rpoD. The expression was analyzed for SP-41 grown in MJ medium for $8 \mathrm{~h}$ (light blue bars) and $24 \mathrm{~h}$ (dark blue bars), in MJ-T medium grown for $8 \mathrm{~h}$ (light orange bars) and 24 h (dark orange bars)

Despite a possible interaction, the cluster I hydrogenase is likely to function also independently from cluster II as a soluble hydrogenase and/or with a different regulation mechanism, under other currently undetermined environmental conditions. Cluster I is located far on the genome from cluster II, and is absent in XCL-2, where it is still well conserved. Other strains exhibiting high hydrogenase oxidation activity in their membrane fraction, such as TH- $55^{T}$, MA- 3 and L- 12 have a group $1 \mathrm{~b}$ hydrogenase. However, their genomes have not yet been sequenced, thus it is unknown if these strains also contain further hydrogenases, as SP-41.

Both XCL-2 and SP-41 are microaerophiles, suggesting that they are able to use $\mathrm{O}_{2}$ as electron acceptor. Similar to the other members of the lineage [21], including XCL2 , SP-41 carries the genes for a cbb3-type cytochrome oxidase (EC 1.9.3.1). This enzyme is found mostly in Proteobacteria, but with representants spread across all bacterial phyla [36], and is typically expressed under microaerophilic conditions [37]. Besides oxygen, hydrogen oxidation can be coupled to the reduction of several other molecules [38]. Therefore, we tried to identify genes, which could suggest the potential use of alternative electron acceptors. A nitrate reductase gene is annotated in SP-41 and XCL-2, but it is not likely to have a respiratory function: denitrification tests on $H$. crunogenus $\mathrm{TH}-$ $55^{T}$ were negative [2]. Five genes are homologs of $d s r E$, a component of dissimilatory sulfite reductase systems. 
However, DsrE may as well be involved also in sulfate oxidation [39], and no further component of a Dsr system is found in the genome. Thus, similar to what was previously noted for XCL-2 [14], we conclude that no other known terminal oxidase, besides $\mathrm{cbb}_{3}$ is present in SP-41.

\section{Homologs of the hydrogenase gene cluster II proteins}

The genomic region containing the hydrogenase gene cluster II is not present in the XCL-2 genome: accordingly, only 3 of the 27 genes in the central part of the region have homologs in XCL-2 (thioredoxin; elongation factor-1-alpha; YeeE/YedE family protein; average blast hit coverage: $95.6 \%$, similarity: $64.9 \%)$. However, several of the proteins have homologs in other organisms (Fig. 4; Additional file 12). The highest number of homologs in the region is found in the genome of Hydrogenovibrio thermophilus MA2-6, which has homologs of all 27 proteins in the region (average blast hit coverage: $97.1 \%$, similarity: $80.0 \%$ ). With the exception of the carbonic anhydrase, which has a homolog (coverage: 99.5\%, similarity: 90.6\%) elsewhere in the MA2-6 genome (cds372), most of the genes are in two regions of the MA2-6 genome (cds1576 to cds1580, cds1590 to cds1610). The genome alignment of MA2-6 to SP-41 shows that the gene order in the two genomes is mostly conserved (Fig. 5). However, the hydrogenase gene cluster is inserted in the MA2-6 genome at a different position and inverted and a region around the cluster in SP-41 is missing in MA2-6 (Fig. 5). The gene order in the hydrogenase region itself is also conserved, although some rearrangements are apparent (Fig. 6). The two groups of hydrogenase-related genes in MA2-6 are separated by 9 genes, mostly related to sulfur assimilation (sulfate adenylyltransferase; phosphoadenosine phosphosulfate reductase; sulfite reductase; cysteine desulfuration protein SufE; siroheme synthase). Of these, only SufE (encoded by MA2-6 cds1588) has a SP41 homolog (cov: 91.8\%; sim: 81.5\%), encoded by a gene located elsewhere on the genome (SP-41 gene GHNINEIG_01718). The presence of genes for enzymes related to assimilatory sulfate reduction next to the hydrogenases has been postulated to be possibly assisting the synthesis of the hydrogenases iron sulfur clusters [21]. However, their absence in SP-41 shows that they are not essential for the hydrogenase activity.

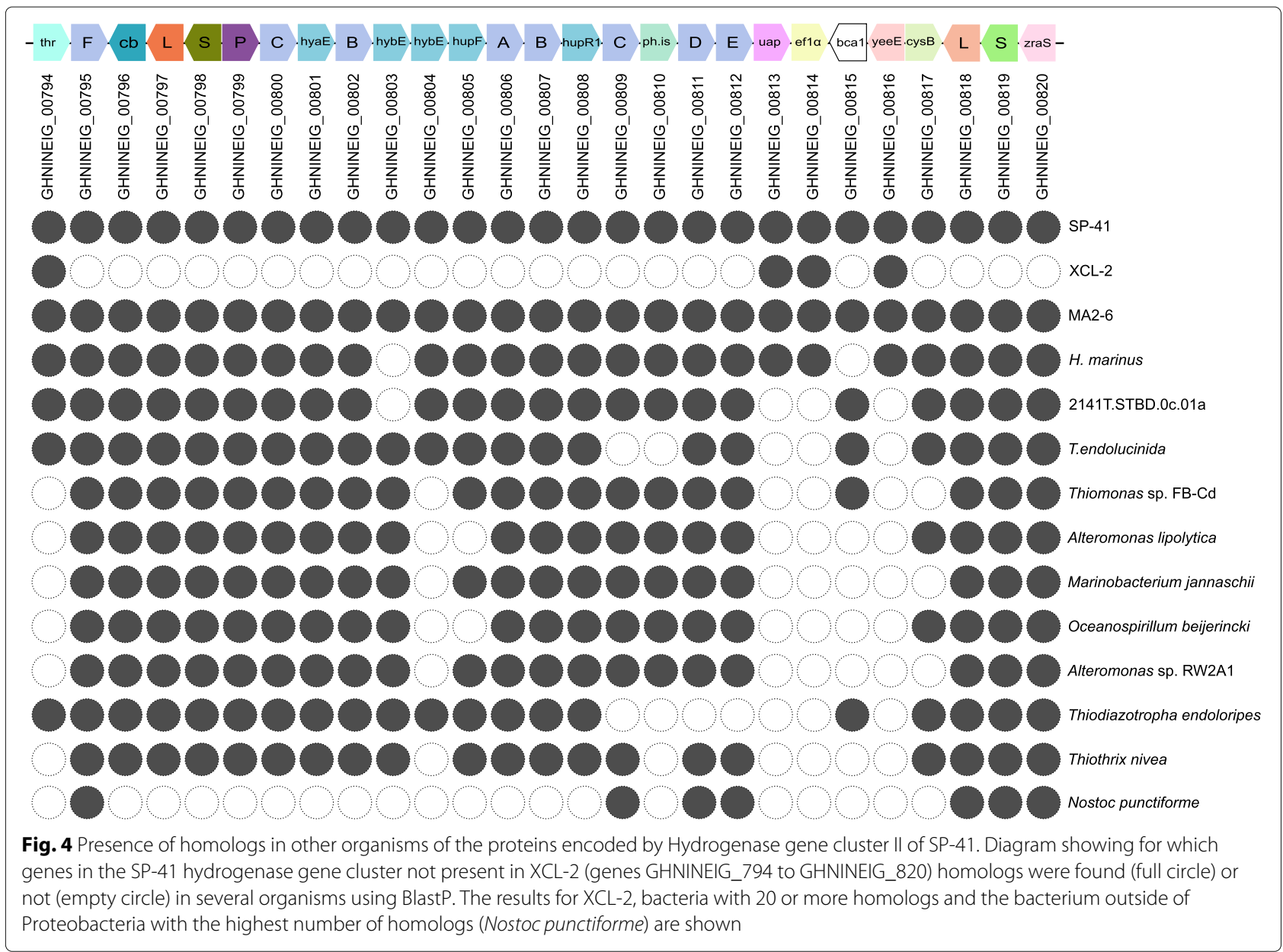




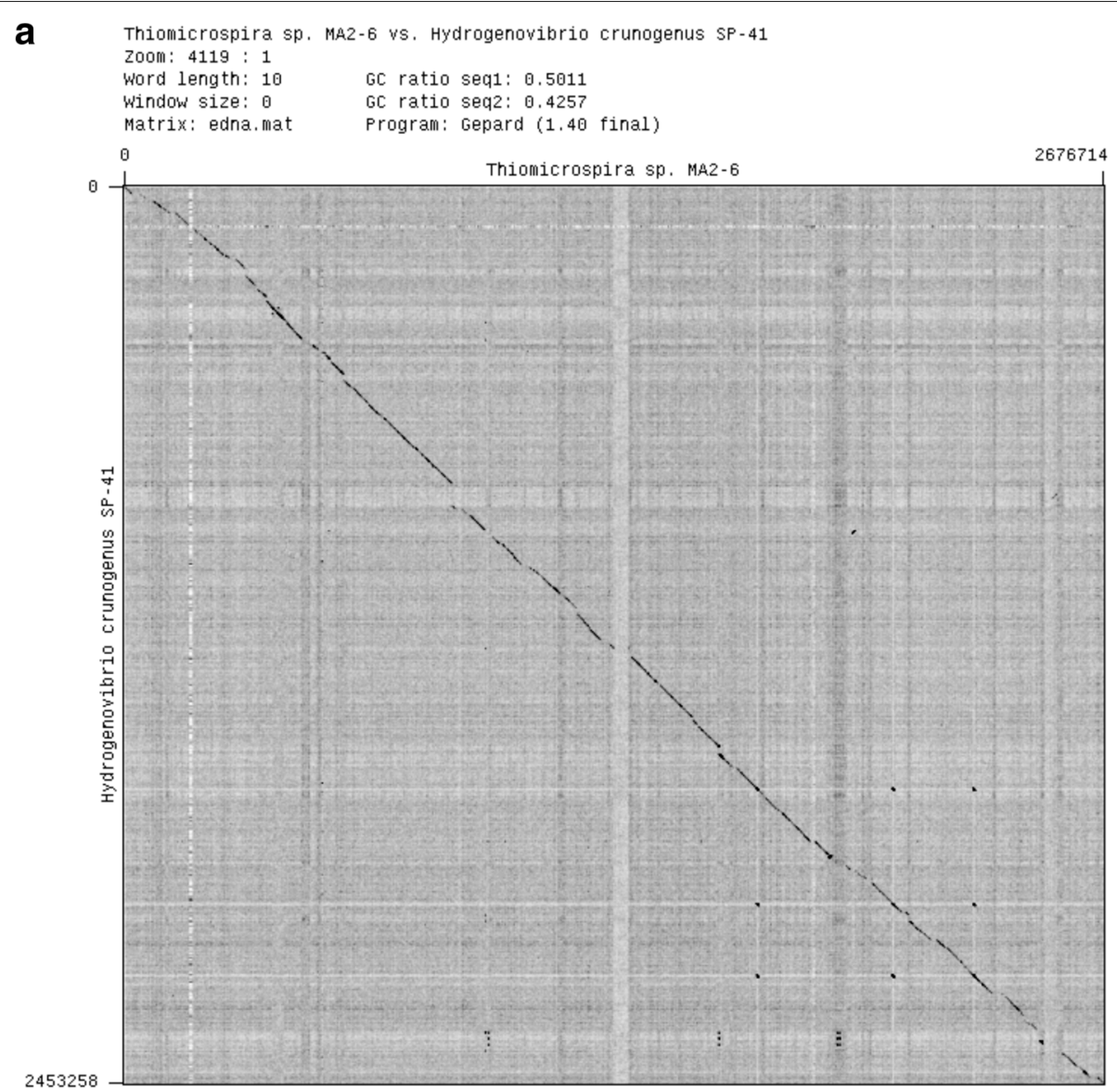

b

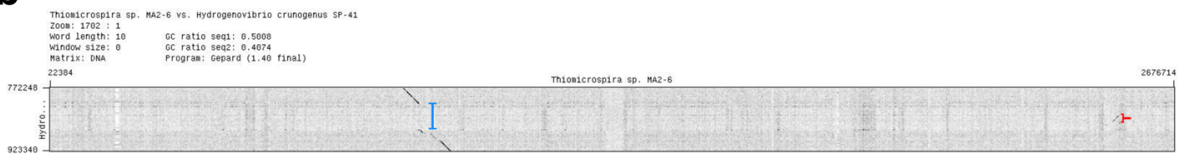

Fig. 5 Alignment of the SP-41 and MA2-6 genomes. Dot plot of the alignment of the SP-41 and MA-2 genomes, for the whole genome a and detail around the hydrogenase gene cluster $\mathbf{b}$. The orientation and starting point of the MA2-6 sequence was changed to match that of SP-41

Another member of the same genus, Hydrogenovibrio marinus $\mathrm{MH}-110$, contains homologs of 25 of the 27 proteins in the region (average blast hit coverage: 97.6\%, similarity: $78.5 \%$ ), missing the hybE/rubredoxin and the carbonic anhydrase (which is not present in the region also in MA2-6). Two genome sequencings were performed independently by two groups ([21] and [17]). In both sequences the order of the genes in the region is very similar to that of MA2-6. The sulfur assimilation genes are also present, but not the Ton-B receptor. The MH110 genome sequence described by [21], contains some additional genes, including a transposase and a duplication of the first hydrogenase and some of the related genes, homologous to SP-41 genes GHNINEIG_00796 to GHNINEIG_00800. However, these genes are not present in the sequence described by [17]. Besides this, the adenylyltransferase small subunit gene is not annotated by [17]. As the two sequencing projects target the same strain, it is unclear if the differences in the sequences represent a genuine rearrangement or if they are sequencing or assembling artifacts.

As XCL-2 is more closely related to SP-41, than the other two strains (Additional file 3), different reconstructions of the evolutionary history of the region remain possible. It might have been acquired by an ancestor of these bacteria and then lost by XCL- 2 and other strains of $H$. crunogenus; in this case, it remains unclear for which reason the region was not maintained, as it confers a larger metabolic flexibility. Alternatively, the region might have been acquired horizontally multiple times; this was considered the most likely explanation to explain the presence of the region in strains of $H$. thermophilus and $H$. marinus 


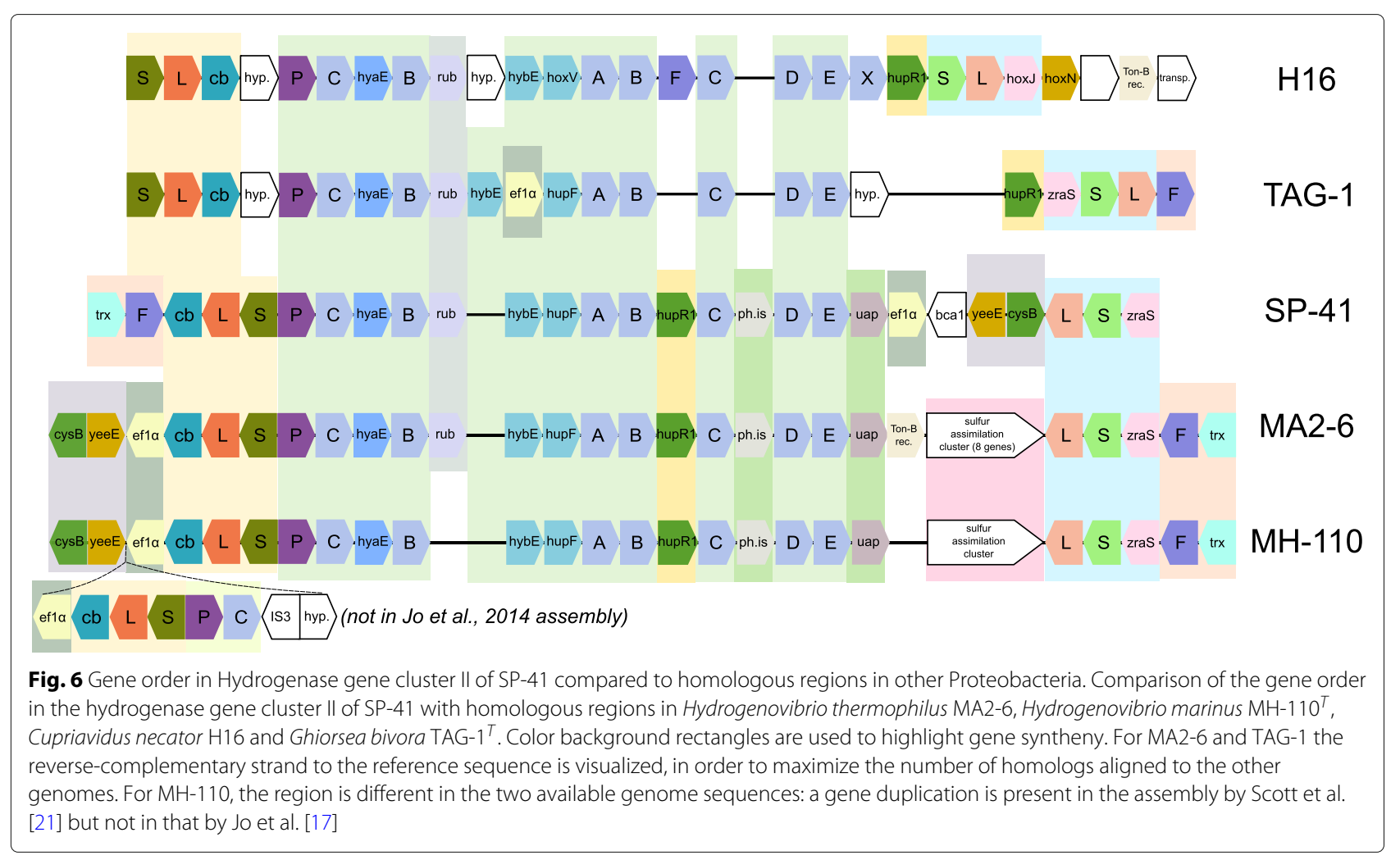

[21], but not in related strains, and could also hold for SP-41. This would explain, why the island is present in different genomic surroundings. It is not known, why this particular hydrogenase island appears so well-suited for members of Hydrogenvibrio. A possible reason could be the presence of the group $2 b$ sensory hydrogenase, which could confer an advantage in the regulation of hydrogenase activity in response to rapid changes in $\mathrm{H}_{2}$ availability.

Outside of the Thiomicrospira / Thiomicrorhabdus / Hydrogenovibrio, 9 other bacterial genomes contain 20 or more homologs of the region, mostly Gammaproteobacteria. The organisms with the next highest number of homologs (Fig. 4) are Gammaproteobacteria living as symbionts, i.e. the Chromatiaceae strain 2141T.STBD.0c.01a (23 homologs), symbiont of the giant shipworm Kuphus polythalamia [40] and Candidatus Endolucinida thiodiazotropha (21 homologs), symbiont of the shallow water bivalve Codakia orbicularis [41]. The highest number of homologs outside of the Gammaproteobacteria is found in Thiomonas sp. FB-Cd (Betaproteobacteria; 21 homologs). Only a few proteins have homologs in organisms outside of Proteobacteria (Additional file 12), with the highest value (7 homologs) found in the cyanobacterium Nostoc punctiforme.

Several genomes of known hydrogen oxidizers from hydrothermal vents have been sequenced. Among the
Proteobacteria, outside of the Thiomicrospira / Thiomicrorhabdus / Hydrogenovibrio clade, these include the complete genomes of Nitratifractor salsuginis E9I37-1 ${ }^{T}$ [42] (Iheya field, Mid-Okinawa Trough), and the draft genomes of Caminibacter mediatlanticus TB- $^{T}{ }$ (MidAtlantic Ridge) [43], Ghiorsea bivora TAG- ${ }^{T}$ (TAG site, Mid-Atlantic Ridge) and SV-108 (Snail Vents, Mariana back-arc) [44], Nitratiruptor tergarcus MI55-1 ${ }^{T}$ (Iheya field, Mid-Okinawa Trough) [45] and Hydrogenimonas thermophila EP1-55-1 ${ }^{T}$ (Karei field, Central Indian Ridge) [46]. Among these genomes, homologs of the SP-41 proteins of the region were found only in Ghiorsea bivora TAG- $1^{T}$. The hydrogenase gene cluster of TAG-1 is almost identical to that of the other strain of the species, SV-108 [44] and is surrounded by an integrase and a recombinase. Only a few differences were found in the gene arrangement, compared to SP-41 (Fig. 6), suggesting a common origin. Among known hydrogen-oxidizing Proteobacteria isolated from other habitats, an homologous region was found to the megaplasmid pHG1 of Cupriavidus necator H16, which codes for four different hydrogenases [47]. The homologous region of pHG1 has a gene arrangement similar to that of Ghiorsea bivora TAG-1 ${ }^{T}$ (Fig. 6). Also, in both strains, differently from SP-41 and the other Hydrogenovibrio strains, all genes in the region have the same orientation. Also for the H16 strain, signs of possible DNA integration 
are present: a transposase gene is found in close proximity (Fig. 6).

Comparison of the functional potential of SP-41 and XCL-2 Besides the regions discussed in the previous sections (i.e. hydrogenase gene cluster II, CRISPR array, prophage) the genomes of SP-41 and XCL-2 contain several other exclusive and divergent regions. In order to assess their potential role in conferring additional metabolism abilities and other environment adaptations, we compared the COG and $\mathrm{KO}$ annotations of the two genomes. COG annotations (Additional file 13) and $\mathrm{KO}$ annotations (Additional file 14) were assigned to an amount of XCL-2 proteins $(62.7 \%$ and $63.9 \%$, respectively) very similar to that of SP-41 (64.0\%; 64.2\%). We identified regions coding for proteins with COG and/or $\mathrm{KO}$ annotations not present in the genome of the other strain. In total (without considering transposases), SP-41 contains 17 such regions, with 47 exclusive $\mathrm{KO}$ and 59 exclusive COG annotations (Additional file 15). Conversely, the SP-41 genome lacks $30 \mathrm{KO}$ and 22 COG annotations, present in 14 exclusive or divergent regions of the XCL-2 genome (Additional file 16). Next, we describe these regions, generally following their order in the genome.

No differences to XCL-2 were observed in the citric acid cycle enzyme: i.e. as XCL-2 [14], SP-41 is also lacking 2oxoglutarate dehydrogenase and malate dehydrogenase. SP-41 carries, similar to MA2-6 and other members of the genus, but not XCL-2 [21] enzymes for the phosphate acetyltransferase-acetate kinase pathway. These are encoded by a small insertion (genes GHNINEIG_00105 and GHNINEIG_00106) to the XCL-2 genome, together with a gene for a putative mobility protein (also present in MA2-6).

The number of membrane transporters is low in XCL-2, reflecting its obligate autotrophic lifestyle [14]. SP-41 has a similar number of KEGG orthology protein annotations included in the KEGG Brite hierarchy "Transporters" (ko02000) (172 in SP-41 and 171 in XCL-2). However, the SP-41 transport proteome covers a wider range of functions (133 KO groups vs. 123 for XCL-2). The transport systems exclusive of SP-41, described below with further detail, are those for urea (UrtABCDE), iron (AfuABC), and mercury (MerRTP), and are located in regions of the genome, which have likely been horizontally acquired.

For the uptake of nitrogen, SP-41 has, in common with XCL-2, nitrate transporter and assimilation proteins NasFED and NasA, the nitrite reductase NirBD, as well as 3 of the 4 Amt ammonia transporters of XCL-2. However, SP-41 contains also an additional region of the genome, including a gene cluster ureDABCEFGH for urease and its accessory proteins, genes for amidase (EC 3.5.1.4) and formamidase (EC 3.5.1.49), nitric oxide reductase activation protein NorD, and a urea transport system (genes
urtABCDE). Some members of the genus Hydrogenovibrio are able to use urea as nitrogen source, e.g. H. marinus [48]. Urease and urea transport genes are also present in other genomes: The closest known relative to the SP-41 region is found in the Hydrogenovibrio kuenenii genome, which contains the urt, amidase and ure genes in the same order (although lacking the NorD and formamidase genes). Genes for urease are also found in the genome of Hydrogenovibrio sp. Milos-T1.

Despite the presence of three NorD genes in SP-41, no other components of a nitric oxide reductase operon were found. Instead, in another single-gene spanning exclusive region of the genome, SP-41 codes for a nitric oxide dioxygenase (EC 1.14.12.17) with a potential role in nitric oxide detoxification [49]. Nitric oxide dioxygenase genes have been previously shown to be particularly prone to horizontal gene transfer [50].

Recently, an iron-oxidizing strain of Hydrogenovibrio, SC-1 has been isolated [51]. It is unknown, if other related strains exist, which share this ability. [21] reported that none of the genomes of Hydrogenovibrio and related genera analyzed in their study contained genes associated with iron oxidation or reduction $(c y c 2, m t o A$, $o m p B, o m c B$ ). This also holds for SP-41. However, SP-41 and XCL-2 differ in their iron transport systems. Both genomes code for the ferrous iron transporters FeoAB, and the $\mathrm{ABC}$ transport system TroABCD capable of transporting $\mathrm{Zn}^{2+}$ and $\mathrm{Mn}^{2+}$, but also $\mathrm{Fe}^{2+}$ and potentially $\mathrm{Fe}^{3+}$ [52]. XCL-2 contains a gene for the high affinity iron transporter EfeU [53], while SP-41 codes for the iron (III) transport proteins AfuABC. The SP-41 afuABC genes (genes GHNINEIG_01422 to GHNINEIG_01424) are located in a short, divergent region followed by two tRNA genes, which are common recombination and insertion points. In the corresponding position of the genome, XCL-2 contains unrelated genes, including a sarcosine oxidase (EC 1.5.3.1) operon. The efeU gene in XCL2 (cds2153) is instead located in a predicted genomic island, a region of the genome, which contains multiple non-homologous sequences in the two genomes and a translocation.

A further exclusive region of SP-41 contains the merRTPA operon (genes GHNINEIG_02228 to GHNINEIG_02231), coding for a mercury transport system and the mercury reductase MerA. It is surrounded by transposase genes, indicating a likely horizontal acquisition. MerA has been previously described as a mercury adaptation system in other deep-sea hydrothermal vents organisms [54]. Functional mer operons have been characterized in several members of the Actinobacteria, Firmicutes, Beta- and Gammaproteobacteria and in Thermus thermophilus [55].

A thiosulfate dehydrogenase (KO K19713, EC 1.8.2.2) was annotated by KEGG BlastKoala in a genomic 
island region of the XCL-2 genome not present in SP41 (cds2156, annotated in the reference sequence as "cytochrome c"). Like XCL-2, SP-41 carries two genes encoding sulfide:quinone oxidoreductase enzymes (sqrA and $s q r F$ ) reflecting its ability to consume hydrogen sulfide at different sulfide levels. Homologs to all Sox genes of XCL-2 were found in SP-41. Like in XCL-2, their arrangement differs from that typical of facultatively autotrophic sulfur-oxidizers, as the system is encoded by three groups of genes (soxXYZA, soxB and soxCD), located in different regions of the genome [14], which may be indicative of a differential regulation of these components [21].

A feature missing in $\mathrm{SP}-41$ is the system for tRNA seleno-modification. This consists in the two genes selD (seledine, water dikinase, EC 2.7.9.3) and selU/ybbB (tRNA 2-selenouridine synthase), which are located in a 2-gene exclusive region of XCL-2 (cds 1052-1053). Selenomodification occurs at tRNAs for Glu, Gln and Lys. The function of this modification is not completely understood, although it is thought to be related to the codonanticodon interaction $[56,57]$.

Both genomes contain a region of the genome coding for sugar/nucleotide metabolism enzymes related to cell wall, membrane and flagellum. The region is partly nonhomologous in the two genomes, although functionally related: Products of the genes in the region include 8 exclusive $\mathrm{KO}$ annotations for SP-41 (FlaA1, WbbJ, RmlA1, RfbB, RfbX, GlpA, OafA, MviM) and 8 exclusive KO in XCL-2 (WcaJ, ManC, Tld, Gmd, RfbC, AscC, RfbG and $\mathrm{FbF}$ ).

\section{Conclusions}

As previously assumed from the comparison of the $16 \mathrm{~S}$ rRNA genes (identity $\geq 99 \%$; [8]), the genome of Hydrogenovibrio sp. SP-41 is closely related to that of Hydrogenovibrio crunogenus XCL-2. Despite a low average nucleotide identity (87.7\%), which would suggest an assignment of the two strains to different species, the alignment of their genomes shows a highly conserved gene order. However, additional sequences are present in both genomes, in short non-homologous regions, or insertions to one of the two genomes in traits where the rest of the sequence is collinear.

Two hydrogenase gene clusters were found in SP41. Cluster I is homologous to the hydrogenase gene cluster in XCL-2 and codes for a group 1b hydrogenase. Cluster II is absent in XCL-2 and codes for two hydrogenases: a group 1d periplasmic membraneanchored hydrogenase and a group $2 \mathrm{~b}$ sensory hydrogenase. Their genomic proximity might indicate interplay of these two hydrogenases, such as regulation of the group 1d hydrogenase by the sensory hydrogenase in response to different hydrogen concentrations in the environment.
Hydrogenase gene cluster II has been likely derived from horizontal gene transfer, as it is surrounded by DNA modification and mobilization genes, and is predicted as genomic island. The closest relatives of this region are found in members of the same genus $(H$. thermophilus MA2-6, H. marinus $\mathrm{MH}-110^{T}$ ). As previously observed [21], it is likely that the region has been acquired multiple times in the lineage, as it is located in different genomic contexts in the different strains. If this is the case, all these strains acquired the hydrogenase from a similar source. However, horizontal acquisition of this gene cluster might be common, well beyond this lineage. Similar regions were found in hydrogen oxidizers, phylogenetically distant from SP-41 and isolated from very different and geographically distant habitats: the Betaproteobacterium Cupriavidus necator H16 (isolated in Germany from soil samples [58]) and two strains of the Zetaproteobacterium Ghiorsea bivora. The latter were isolated from similar habitats (iron mats of hydrothermal vents) but far away from each other (TAG- ${ }^{T}$ : TAG vent site, Mid-Atlantic Ridge; SV-108: Snail Vents site, Mariana back-arc; [44]). Also in these genomes, genes related to DNA mobility were found in proximity of their hydrogenase gene clusters.

Both MH-110 and MA2-6 are able to grow on hydrogen, as SP-41, thus likely the presence of this region explains the difference in this ability from XCL-2, which lacks the region. We showed that both the large subunit genes of cluster II group 1d hydrogenase and of cluster I group $1 b$ hydrogenase are expressed during $\mathrm{H}_{2}$ consumption, and their expression is higher when $\mathrm{H}_{2}$ is the only available electron donor. As both hydrogenases are expressed, we hypothesize that elements of both hydrogenase gene clusters could interact in SP-41 during the observed hydrogen oxidation activity. This could explain the differences in activity rate and hydrogen affinity of SP-41 to MA2-6, both containing cluster II. However, if this is the case, this is probably not the only activity mechanism of cluster I, as interaction cannot explain its presence and conservation in XCL-2, where the cluster II is absent.

Besides the ability of growing on hydrogen, horizontal transfer of genetic material appears to play an important role in shaping the genome of SP-41. This is reflected by the higher number of transposases (compared to XCL-2) located in multiple small regions not present in the XCL-2 genome. These regions often contain signs of possible DNA mobilization, such as the presence of genes for transposases, integrases and DNA modification, or a genomic position next to common insertion points, such as tRNA genes. In an environment where DNA mobility is likely very high, the necessity may also arise to protect against unwanted sequences, such as invading plasmids or viruses; this 
might explain the presence of a CRISPR locus, not present in XCL-2. In a group of autotrophic Protobacteria genomes the average number of transposases appears to be higher where CRISPR loci are present. However, we found also several counter-examples, where presence of CRISPRs and abundance of transposases are not correlated. Thus, further studies are necessary to understand the observed correlation and which other factors may play a role.

The inserted DNA confers to SP-41 features absent in $\mathrm{XCL}-2$, such as a urease and transport system for urea, a transport system for ferrous iron and a detoxification system for mercury. These may be important for the survival in the specific environment. Adaptations to the habitat are a common feature of Thiomicrospira, Hydrogenovibrio and Thiomicrorhabdus species, explaining their prevalence in multiple heterogeneous environments [21]. Besides this, as postulated for other hydrothermally influenced habitats, high levels of horizontal gene transfer may confer an advantage to the bacterial community as a whole [28].

\section{Methods}

\section{Cultivation of SP-41 isolate and enrichment}

An enrichment culture containing SP-41 as well as the isolated strain SP-41 were previously obtained and cultivated in our laboratory [9]. For later DNA isolation, the Hydrogenovibrio sp. SP-41 isolate was grown in 400 $\mathrm{ml}$ T-ASW with a $\mathrm{pH}$ of 7.5-7.8 [59] in $1 \mathrm{l}$ flasks at 28 ${ }^{\circ} \mathrm{C}$ for approximately 2.5 days. The $\mathrm{pH}$ decrease of the medium, inoculated with a fresh pre-culture, was monitored by the color change of the phenol red contained in the medium. When necessary, the $\mathrm{pH}$ was increased with a $5 \% \mathrm{NaHCO}_{3}$ solution. The cells were harvested by centrifugation at 17,000 g (Sorvall TC 6 Plus Centrifuge, Thermo Fisher Scientific Inc.), washed in $1 \mathrm{x}$ PBS buffer and pelleted again by centrifugation. The cell pellet was stored at $-20{ }^{\circ} \mathrm{C}$ until further use. An additional purity check of the culture was performed with fluorescence in situ hybridization (FISH) as described before [9], showing a SP-41 specific probe signal for every DAPI-stained cell.

Additionally, the enrichment culture dominated by Hydrogenovibrio sp. SP-41 was grown in $120 \mathrm{ml}$ serum bottles filled with $50 \mathrm{ml}$ of MJ medium. The headspace of the bottles was replaced by a gas mixture of $\mathrm{H}_{2}: \mathrm{CO}_{2}: \mathrm{O}_{2}$ (79:20:1; Westfalen AG, Münster, Germany) as stated before [9]. The culture was incubated for approximately five weeks at $28{ }^{\circ} \mathrm{C}$ under weekly regassing of the head space. After harvesting three liters of the culture at 17,000 g (Sorvall TC 6 Plus Centrifuge, Thermo Fisher Scientific Inc., Waltham, MA, USA), sedimented cells were washed in $50 \mathrm{mM}$ Tris buffer (pH 8.0). The repelleted cells were stored at $-20{ }^{\circ} \mathrm{C}$ until further use.
Analysis of the expression of the [NiFi]-hydrogenase genes For the qRT-PCR experiments, Hydrogenovibrio SP-41 was grown in $\mathrm{MJ}(1400 \mathrm{~mL}$ per biological replicate) and MJ-T media (700 mL per biological replicate) with an atmosphere of $\mathrm{H}_{2}: \mathrm{CO}_{2}: \mathrm{O}_{2}: \mathrm{He}(2: 20: 1: 78 \%(v / v))$ as described in [9]. Cells were harvested after 8 and 24 h of incubation at $28{ }^{\circ} \mathrm{C}$ by centrifugation at $17,000 \mathrm{~g}$ and $4{ }^{\circ} \mathrm{C}$ for $30 \mathrm{~min}$ (Sorvall LYNX 4000, Thermo Scientific, Waltham, MA, USA). After a washing step with $1.5 \mathrm{~mL} 1 \mathrm{x}$ PBS buffer, cell pellets were stored at $-80{ }^{\circ} \mathrm{C}$. For isolation of total RNA, the cell pellets were resuspended in $500 \mu \mathrm{L}$ TriReagent (Zymo Research, Irvine, CA, USA), transferred to ZR Bashing Bead Lysis Tubes (0.1-0.5 mm, Zymo Research) and cells were lysed by vortexing at full speed for $10 \mathrm{~min}$. RNA was purified from the cell lysates using the Direct-zol ${ }^{\mathrm{m}} \mathrm{RNA}$ Miniprep Kit (Zymo Research) according to the manufacturer's instructions, followed by an additional DNase treatment with the DNase Max Kit (Qiagen, Hilden Germany). The total (DNA-free) RNA was transcribed into cDNA using the SuperScript ${ }^{\mathrm{mm}} \mathrm{VILO}^{\mathrm{mm}}$ Master Mix (Invitrogen, Carlsbad, CA, USA) according to the manufacturer's instructions with up to $2.5 \mu \mathrm{g}$ RNA. The resulting cDNA was purified with the DNA clean and concentrator-5 Kit (Zymo Research) and eluted with $20 \mu \mathrm{L}$ of elution buffer $(10 \mathrm{mM}$ tris- $\mathrm{HCl}, \mathrm{pH}$ 8.5). The following primer pairs were used to perform qRT-PCR experiments, yielding products of $\approx 150 \mathrm{bp}$ : (i) $\quad r p o D-1337 F\left(5^{\prime}\right.$-ACCGTATTCAGCGTCAGTTG-3') and rpoD-1476R (5'-TGGCGTTTCCATTGAGATCG-3') to amplify the housekeeping gene $r p o D$, (ii) $40 F$ and $189 R$ (see [9]) for the amplification of the gene for the large subunit of the group $1 \mathrm{~b}$ hydrogenase in hydrogenase gene cluster I and (iii) hynL2-1260F (5' - CGCACAAGGTGTTGAGTACG - 3') and hynL2-1409R (5'-GCTCGGGCTAAAGTTCTTCC-3') to amplify the gene for the large subunit of the group 1d hydrogenase in hydrogenase gene cluster II. The amplification was performed using the SYBR $^{\mathrm{m} \text { N}}$ Select Master Mix (Applied Biosystems, Foster City, CA, USA) with $25 \mathrm{ng}$ of cDNA as template in a $20 \mu \mathrm{L}$ reaction. The qPCR was run in a C1000 Touch Thermal Cycler equipped with a CFX 96 Real Time System (Bio-Rad Laboratories Inc., Hercules, CA, USA) under the following conditions: initial denaturation at $98{ }^{\circ} \mathrm{C}$ for $2 \mathrm{~min}$; 40 cycles of $98{ }^{\circ} \mathrm{C}$ for $15 \mathrm{~s}, 52{ }^{\circ} \mathrm{C}$ for $20 \mathrm{~s}$ and $72{ }^{\circ} \mathrm{C}$ for $30 \mathrm{~s}$. Non-template as well as non-RT (i.e. RNA) controls were performed for each primer pair in every run. Three technical and biological replicates, each, were performed for the MJ-T samples. For the MJ media samples, only the $24 \mathrm{~h}$ incubation of one sample yielded sufficient RNA and cDNA material. Therefore, only one biological replicate (with three technical replicates) could be analyzed for this condition. The inter-run comparability was 
ensured by repeating a reaction (in triplicate) on the next plate as calibrator. The relative quantities of expressed hydrogenase genes were calculated and normalized to the single-copy housekeeping gene $r p o D$. Technical and biological replicates were arithmetically averaged and an overall mean value was calculated. Standard deviations of the technical replicates were propagated forward by applying the Gaussian propagation of error to calculate the error of the overall mean values.

\section{DNA extraction and sequencing of SP-41 enrichment and isolate}

The DNA isolation of SP-41 was performed using the MagAttract HMW DNA Kit (Qiagen, Hilden, Germany) according to the manufacturer's instructions. Residual RNA was removed via digestion with $10 \mu / \mathrm{ml}$ of DNasefree Rnase A (Applichem GmbH, Darmstadt, Germany) for $2 \mathrm{~h}$ at room temperature. The DNA was subsequently purified using the SureClean Plus Kit (Bioline GmbH, Luckenwalde, Germany) according to the manufacturer's protocol but avoiding the co-precipitant. The purity of the DNA was checked by PCR amplification of the $16 \mathrm{~S}$ rRNA gene as well as hynL genes, followed by cloning and sequencing of the PCR products as described before [9]. The DNA of the SP-41 isolate was sequenced using the PacBio RSII technique (Pacific BioSciences, Menlo Park, CA, USA) at GATC Biotech AG (Konstanz, Germany). DNA of the enrichment culture was isolated according to Böhnke and Perner [60] and the presence of SP41's DNA was checked analogously to the purity check of the DNA of the SP-41 isolate. Two DNA libraries (a mate-pair and a fragment library) were constructed and paired-end sequenced by Microsynth AG (Balgach, Switzerland) using the Illumina MiSeq platform (Illumina, San Diego, CA, USA). Quality control for the sequencing reads of both approaches was performed using FastQC v. $0.11 .5[61]$.

\section{Assembly of the SP-41 genome}

The SP-41 Pacific Biosciences reads were assembled using Canu v. 1.6 [62] using an estimated genome size parameter of $2.8 \mathrm{Mbp}$. Using circlator v. 1.5.2 [63] with default parameters, the assembly was circularized and oriented to start from the dnaA gene. The Illumina reads obtained from the SP-41 enrichment culture were mapped to the assembly using bwa mem v. 0.7.15 [64], with default parameters. The resulting alignments were sorted and indexed using samtools v. 1.4.1 [65]. Using Pilon v. 1.22 [66] with the parameters - fix all and -mindepth 0.5 , the alignments were used to correct the assembly. This was performed in three subsequent steps, using paired end reads from the fragment library in the first step, reads classified as paired end from the mate pair library in the second step, and reads classified as mate pair reads from the mate pair library in the third step.

\section{Annotation of the SP-41 genome}

The genomic sequence of SP-41 was first annotated using the Prokka pipeline v. 1.12 [22] using the option - compliant. The protein sequences from all annotated genes for which the product annotation was "hypothetical protein" were aligned to the RefSeq Protein database by Blast. Only results with query coverage of at least $80 \%$ and a maximum e-value of $10^{-5}$ were considered. Hits to proteins whose product description was "hypothetical protein" or contained one of the strings "predicted protein", "unknown function" or "domain-containing protein" were filtered out. For each of the queries, all remaining hits to proteins of XCL-2, MA2- 6 and the highest score hit among all others were retained. The matching proteins in this hit set were extracted from the Refseq Protein database and used as a custom protein database for a second pass of annotation using Prokka. In the final Prokka annotation, 10 product descriptions of CDS features contained the word "partial", not allowed by Genbank; the word was removed and the product was described as putative.

\section{Alignment to Refseq Protein}

The Blast database of all NCBI Refseq proteins was obtained on 2017/10/19 using update_blastdb.pl from NCBI Blast+ v.2.7.0 suite [67]. The protein sequences were aligned to the database using blastp v. 2.7.0 with default parameters. Hits with query coverage smaller than $80 \%$ or an e-value higher than $10^{-5}$ were discarded.

\section{Comparison to related genomes}

The sequence (Fasta) and annotation (GFF3) of other related bacterial genomes were obtained from the NCBI Refseq database [68], with the following accession numbers: Hydrogenovibrio crunogenus XCL-2: NC_007520.2; Hydrogenovibrio thermophilus MA26: NZ_JOMK01000001.1; Hydrogenovibrio marinus MH-110 ${ }^{T} /$ DSM11271 ${ }^{T}$ : NZ_JOML01000001.1 to NZ_JOML01000003.1; Thiomicrospira aerophila $\mathrm{AL}^{T}$ : NZ_CP007030.1; Thiomicrospira cyclica $\mathrm{ALM1}^{T}$ : NC_015581.1; Hydrogenovibrio halophilus DSM $15072^{T}$ : NZ_KB913033.1; Hydrogenovibrio sp. Milos-T1: NZ_JQMT01000001.1; Thiomicrospira pelophila DSM $1534^{T}$ : NZ_JOMR01000001.1. The pairwise average nucleotide identity (ANI) of these genomes was computed by Jspecies v. 1.2.1 [69] using the ANIb algorithm [25].

\section{Comparison of the arrangement of hydrogenase gene cluster II}

We compared the arrangement of the genes in SP-41 hydrogenase gene cluster II with that of the similar 
clusters in MA2-6 and MH-110 (organisms with the highest number of homologs in the region). Furthermore we also included in the comparison other related genomic sequences: a second assembly of the Hydrogenovibrio marinus $\mathrm{MH}-110^{T}$ genome, described by [17] (GenBank, accession JMIU01000000), the megaplasmid pHG1 of Cupriavidus necator H16 (Refseq NC_005241.1) and the genomes of Ghiorsea bivora TAG- ${ }^{T}$ (Refseq NZ_JQLW00000000.1), Nitratifractor salsuginis E9I37-1 ${ }^{T}$ (Refseq NC_014935.1) Caminibacter mediatlanticus TB-2 ${ }^{T}$ (Refseq NZ_ABCJ00000000.1), Nitratiruptor tergarcus MI55-1 ${ }^{T}$ (Refseq NZ_FWWZ00000000.1) and Hydrogenimonas thermophila EP1-55-1 ${ }^{T}$ (Refseq NZ_FOXB00000000.1). Among these, only genomes where an inspection of the annotations in proximity of the hydrogenase clusters revealed a similar structure to that of hydrogenase gene cluster II of SP-41 were further considered (strains TAG-1 and H16). For the illustration, we manually re-annotated the gene names and functions on the base of the BLASTp alignments of their products to the SP-41 and NCBI Refseq proteins.

\section{Annotation of genomic islands}

Lists of genomic islands predictions of were obtained from of IslandViewer4 [26], from the database of precomputed results (for XCL-2, accession NC_007520.2) or computed using the interactive web application (for the SP-41 genome). Thereby the results for XCL-2 are based on merging the pre-computed predictions by IslandPath-DIMOB [27] and Islander [70], while for uploaded genomes only IslandPath-DIMOB predictions are computed. Therefore we run the standalone version of Islander v. 1.2 with default parameters on the SP41 genome; as it did not predict any further island, no merging was necessary.

\section{Pairwise alignment of genome sequence and annotation} Dot plots of the alignments of the SP-41 genome against other related genomes were obtained using Gerard v. 1.4 [71] using default parameters. Pairwise alignments of the SP-41 genome against other related genomes were computed using progressiveMauve [72] using default parameters. Using an custom python script, each region of the Mauve alignment of SP-41 and XCL- 2 was classified in common or exclusive of one of the two genomes. For common regions, collinear features were identified based on their position and on BLAST alignments of the protein sequences of the two genomes. Thereby only hits with query coverage of $80 \%$ and maximal e-value of $10^{-5}$ were considered.

\section{Comparative functional annotation}

The assignment of $\mathrm{KO}$ annotations to the proteins of the SP-41 and the XCL-2 genomes was performed using
KEGG Blastkoala [24], selecting the prokaryotes taxonomy group and the species_prokaryotes database. Differences in $\mathrm{KO}$ annotations of orthologs in the two strains where eliminated by transferring the $\mathrm{KO}$ annotation among the homologs found by blastp alignment. The results were mapped to the KEGG Pathways, Brite terms and Modules ontologies using KEGG mapper v. 3.1 [73]. The assignment of COG annotations to the proteins of the SP-41 and the XCL-2 genomes was performed using CD-search [23], selecting the COG database [74] and using default parameters. Sets of common and exclusive annotations were identified using custom Python scripts.

\section{Circular plot of the SP-41 genome}

A circular plot of the SP-41 genome was created using Circos v. 0.64 [75]. The data for the GC\% plot track was computed by a custom Ruby script as average value in windows of 128 nucleotides along the genome. Functional categories for the protein-coding genes were computed from the CD-search COG assignments, using the mapping (cognames2003-2014.tab) and the names of the functional categories (fun2 $003-2014$. tab) available in the NCBI FTP server at ftp://ftp.ncbi.nih.gov/pub/COG/COG2014/data/.

\section{Number of tranposases and CRISPRs presence in autotrophic Proteobacteria}

A list of autotrophic Protobacteria genomes and a list of transposase PFAM [76] families (pfam00872, pfam01527, pfam01609, pfam01797, pfam02371, pfam05598, pfam09299, pfam12762, pfam12784) were obtained from [21]. The presence or absence of a CRISPR annotation and the sum of the number of transposases in the PFAM families were obtained from IMG/M [77]. The hypothesis that the number of transposases for genomes with a CRISPR was from a distribution with a higher mean than that for genomes without a CRISPR was tested using a Welch's one-sided t-test as implemented by the $\mathrm{R}$ function $\mathrm{t}$. test, with the parameters var. equal=N, alternative="greater". The significance level was set to 0.05 .

\section{Multiple sequence alignment of the 16S rRNA genes}

The three 16S rRNA genes of SP-41 (GHNINEIG_01594, GHNINEIG_01882, GHNINEIG_02064), XCL-2 (rna38, rna45, rna53) and Escherichia coli K-12 (obtained from EcoCyc [78], accession EG30084) were aligned using muscle v. 3.8.31 [79]. As the three copies of XCL-2 were identical, only one was retained in the final alignment. The position of hypervariable regions was annotated in the alignment based on the coordinates of the regions in the E. coli $\mathrm{K}-12$ sequence [80]. 


\section{Additional files}

Additional file 1: COG annotations of SP-41 proteins. COG assignments by CD-search [23] using the COG database [74] to the proteins encoded by the SP-41 genome. COG annotations were assigned to $64.0 \%$ of the SP-41. proteins. (CSV $44 \mathrm{~kb}$ )

Additional file 2: $\mathrm{KO}$ annotations of SP-41 proteins. $\mathrm{KO}$ assignments by Blastkoala [24], using the prokaryotes taxonomy group and the species_prokaryotes database to the proteins encoded by the SP-41 genome. KO annotations were assigned to $64.2 \%$ of the SP-41 proteins. (CSV $118 \mathrm{~kb})$

Additional file 3: Pairwise average nucleotide identity. Pairwise average nucleotide identity (ANI) computed using the ANIb algorithm, of the genome of SP-41 and related genomes. (CSV $1 \mathrm{~kb}$ )

Additional file 4: Best Blast hit in XCL-2 proteins for each protein of SP-41. Table reporting the results of the alignment of SP-41 proteins to the XCL-2 proteins using BlastP. Only the best hit (if any) for each SP-41 protein is reported. (CSV $314 \mathrm{~kb})$

Additional file 5: Alignment of the $16 \mathrm{~S}$ rRNA genes of SP-41 and XCL-2. Multiple sequence alignment of the three $16 \mathrm{~S}$ rRNA genes of SP-41, XCL-2 (in a single sequence, as its 3 copies are identical) and E. coli K12. The borders of the hypervariable regions in the alignment were annotated, based on their coordinates in the E. coli sequence. (TXT $17 \mathrm{~kb}$ )

Additional file 6: Base calling errors of previous SP-41 16S rRNA sequencing. Initial part of the chromatogram of the 165 rRNA gene sequencing of SP-41 with the 26F primer, described in [9]. The regions with a light red background contain bases which are different in one of three $16 \mathrm{~S}$ rRNA gene copies of SP-41. The base calling was assuming that the sequence was in single copy, thus called the most common base. From 5', this happened in 1 position in the first highlighed region, 4 positions in the second highlighed region and 2 positions in third highlighed region. (PDF $1801 \mathrm{~kb})$

Additional file 7: Collinear, divergent, exclusive and translocated regions of the alignment of the SP-41 and XCL-2 genomes. Coordinates of the regions of the alignment of the genomes of SP-41 and XCL-2, classified as collinear (same gene order), translocated (same gene order but moved in another genomic context), divergent (two different regions present in the two genomes, with different genes), exclusive (additional region with at least one annotated feature present only in one of the two genome, while in the other genome the region is absent, or a different sequence, with no annotated features is present). (CSV $16 \mathrm{~kb}$ )

Additional file 8: Coordinates of the genomic islands of SP-41 and XCL-2. Coordinates of the 7 genomic islands in the SP-41 genome and of the 9 genomic islands in the XCL-2 genome, as predicted by IslandViewer [26]. (CSV $1 \mathrm{~kb}$ )

Additional file 9: Coding sequences of SP-41 overlapping genomic islands. Coordinates and product description of coding sequence (CDS) annotations of the SP-41 genome partially or completely overlapping genomic islands predicted by IslandViewer [26]. (CSV $12 \mathrm{~kb}$ )

Additional file 10: Coding sequences of XCL-2 overlapping genomic islands. Coordinates and product description of coding sequence (CDS) annotations of the XCL-2 genome partially or completely overlapping genomic islands predicted by IslandViewer [26]. (CSV $19 \mathrm{~kb}$ )

Additional file 11: Presence of CRISPR loci and transposase abundance in genomes of a group of autotroph Proteobacteria. Presence of CRISPRs and transposases belonging to Pfam families previously selected for a similar analysis by [21] in a set of genomes of autotroph proteobacterial strains, described in the same study. The annotation data (number of CRISPRs and Pfam annotations) was obtained from the IMG/M platform [77]. The file also contains a transcript of the $R$ session in which the statistical significance of the differences was assessed.(CSV $7 \mathrm{~kb}$ )

Additional file 12: Homologs of the Hydrogenase Gene Cluster II proteins. Hits by BlastP in the NCBI Refseq Protein database of the protein encoded by the Hydrogenase Gene Cluster II region of the SP-41 genome. (CSV $1389 \mathrm{~kb})$
Additional file 13: COG annotations of XCL-2 proteins. COG assignments by CD-search [23] using the COG database [74] to the proteins encoded by the XCL-2 genome. COG annotations were assigned to $62.7 \%$ of the XCL-2 proteins. (CSV $42 \mathrm{~kb}$ )

Additional file 14: $\mathrm{KO}$ annotations of $\mathrm{XCL}-2$ proteins. $\mathrm{KO}$ assignments by Blastkoala [24], using the prokaryotes taxonomy group and the species_prokaryotes database to the proteins encoded by the XCL-2 genome. KO annotations were assigned to $63.9 \%$ of the XCL-2 proteins. (CSV $115 \mathrm{~kb}$ )

Additional file 15: Regions of the SP-41 genome with exclusive KO/COG annotations. Regions of the SP-41 genome containing genes coding for protein assigned to ortholog groups (KO, COG) not present in XCL-2. (PDF $86 \mathrm{~kb})$

Additional file 16: Regions of the XCL-2 genome with exclusive $\mathrm{KO} / \mathrm{COG}$ annotations. Regions of the XCL-2 genome containing genes coding for protein assigned to ortholog groups (KO, COG) not present in SP-41. (PDF $83 \mathrm{~kb}$ )

\section{Abbreviations}

COG: Clusters of Orthologous Groups; CRISPR: clustered regularly interspaced short palindromic repeats; KO: KEGG Orthology; qRT-PCR: quantitative reverse transcriptase polymerase chain reaction

\section{Acknowledgements}

We appreciate all the precursor work by Moritz Hansen in culturing, isolating and describing this isolate making the sequence project possible. We would like to thank Stefan Kurtz (Center for Bioinformatics, University of Hamburg) for helpful discussions about the bioinformatics analyses.

\section{Funding}

Nicole Adam was supported by the research grant DFG PE1549-6/3 from the German Science Foundation. The funding body had no role in study design, data collection and analysis, interpretation of the results or in writing the manuscript.

\section{Availability of data and materials}

The sequence and annotation of the genome assembly of SP- 41 were deposited to the NCBI GenBank database, Accession CP032096.

\section{Authors' contributions}

GG and MP planned the sequencing, and wrote the paper. GG also performed the bioinformatics analyses. NA provided DNA material for sequencing of SP-41, performed the GRT-PCR analysis and helped with text editing. All authors have read and approved the manuscript.

\section{Ethics approval and consent to participate}

Not applicable.

\section{Consent for publication}

Not applicable.

\section{Competing interests}

The authors declare that they have no competing interests.

\section{Publisher's Note}

Springer Nature remains neutral with regard to jurisdictional claims in published maps and institutional affiliations.

\section{Author details}

${ }^{1}$ Universität Hamburg, MIN-Fakultät, ZBH - Center for Bioinformatics, Bundesstraße 43, 20146 Hamburg, Germany. ${ }^{2}$ GEOMAR Helmholtz Center for Ocean Research Kiel, Geomicrobiology, Wischhofstr. 1-3, 24148 Kiel, Germany. ${ }^{3}$ previous address: Universität Hamburg, MIN-Fakultät, Biocenter Klein Flottbek, Molecular Biology of Microbial Consortia, Ohnhorststr. 18, 22609 Hamburg, Germany. 


\section{References}

1. Boden R, Scott KM, Williams J, Russel S, Antonen K, Rae AW, Hutt LP. An evaluation of Thiomicrospira, Hydrogenovibrio and Thioalkalimicrobium: Reclassification of four species of Thiomicrospira to each Thiomicrorhabdus gen. nov. and Hydrogenovibrio, and reclassification of all four species of Thioalkalimicrobium to Thiomic. Int J Syst Evol Microbiol. 2017;67(5): 1140-51. https://doi.org/10.1099/ijsem.0.001855.

2. Jannash H, Wirsen C, Nelson D, Robertson L. Thiomicrospira crunogena sp. nov., a Colorless, Sulfur-Oxidizing Bacterium from a Deep-Sea Hydrothermal Vent. Int J Syst Bacteriol. 1985;35(4):422-4. https://doi.org/ 10.1099/00207713-35-4-422.

3. Ruby EG, Jannasch HW. Physiological characteristics of Thiomicrospira sp. strain L-12 isolated from deep-sea hydrothermal vents. J Bacteriol. 1982;149(1):161-5.

4. Ahmad A, Barry JP, Nelson DC. Phylogenetic affinity of a wide, vacuolate, nitrate-accumulating Beggiatoa sp. from Monterey Canyon, California, with Thioploca spp,. Appl Environ Microbiol. 1999;65(1):270-7.

5. Petri R, Podgorsek L, Imhoff JF. Phylogeny and distribution of the soxB gene among thiosulfate-oxidizing bacteria. FEMS Microbiol Lett. 2001;197(2):171-8. https://doi.org/10.1016/S0378-1097(01)00111-2.

6. Nunoura T, Takai K. Comparison of microbial communities associated with phase-separation- induced hydrothermal fluids at the Yonaguni Knoll IV hydrothermal field, the Southern Okinawa Trough. FEMS Microbiol Ecol. 2009:67(3):351-70. https://doi.org/10.1111/j.1574-6941.2008.00636.x.

7. Wirsen CO, Brinkhoff T, Kuever J, Muyzer G, Molyneaux S, Jannasch HW. Comparison of a new Thiomicrospira strain from the Mid-Atlantic Ridge with known hydrothermal vent isolates. Appl Environ Microbiol. 1998;64(10):4057-9.

8. Hansen M, Perner M. Hydrogenase gene distribution and $\mathrm{H}_{2}$ consumption ability within the Thiomicrospira lineage. Front Microbiol. 2016;7(FEB):1-13. https://doi.org/10.3389/fmicb.2016.00099.

9. Hansen M, Perner M. A novel hydrogen oxidizer amidst the sulfur-oxidizing Thiomicrospira lineage. ISME J. 2015;9(3):696-707. https:// doi.org/10.1038/ismej.2014.173.

10. Kuenen JG, Veldkamp H. Thiomicrospira pelophila, gen. n., sp. n., a new obligately chemolithotrophic colourless sulfur bacterium. Anton Leeuw J Microbiol Serol. 1972;38(3):241-56. https://doi.org/10.1007/BF02328096.

11. Nishihara $H$, Igarashi $Y$, Kodama T. Isolation of an obligately chemolithoautotrophic, halophilic and aerobic hydrogen-oxidizing bacterium from marine environment. Arch Microbiol. 1989;152(1):39-43. https://doi.org/10.1007/BF00447009.

12. Nishihara $H$, Miyata $Y$, Miyashita $Y$, Bernhard M, Pohlmann A, Friedrich B, Takamura Y. Analysis of the molecular species of hydrogenase in the cells of an obligately chemolithoautotrophic, marine hydrogenoxidizing bacterium, Hydrogenovibrio marinus. Biosci Biotechnol Biochem. 2001;65:2780-4. https://doi.org/10.1271/bbb.65.2780.

13. Hansen M, Perner M. Reasons for Thiomicrospira crunogena's recalcitrance towards previous attempts to detect its hydrogen consumption ability. Environ Microbiol Rep. 2016;8(1):53-7. https://doi. org/10.1111/1758-2229.12350.

14. Scott KM, Sievert SM, Abril FN, Ball La, Barrett CJ, Blake Ra, Boller AJ, Chain PSG, Clark Ja, Davis CR, Detter C, Do KF, Dobrinski KP, Faza BI, Fitzpatrick Ka, Freyermuth SK, Harmer TL, Hauser L, Hügler M, Kerfeld Ca, Klotz MG, Kong WW, Land M, Lapidus A, Larimer FW, Longo DL, Lucas S, Malfatti Sa, Massey SE, Martin DD, McCuddin Z, Meyer F, Moore JL, Ocampo LH, Paul JH, Paulsen IT, Reep DK, Ren Q, Ross RL, Sato PY, Thomas P, Tinkham LE, Zeruth GT. The genome of deep-sea vent chemolithoautotroph Thiomicrospira crunogena XCL-2,. PLoS Biol. 2006;4(12):383. https://doi.org/10.1371/journal.pbio.0040383.

15. Watsuji TO, Hada E, Miyazaki M, Ichimura M, Takai K. Thiomicrospira hydrogeniphila sp. nov., an aerobic, hydrogen- and sulfur-oxidizing chemolithoautotroph isolated from a seawater tank containing a block of beef tallow. Int J Syst Evol Microbiol. 2016;66(9):3688-93. https://doi.org/ 10.1099/ijsem.0.001250.

16. Brazelton WJ, Baross Ja. Metagenomic comparison of two Thiomicrospira lineages inhabiting contrasting deep-sea hydrothermal environments. PloS One. 2010;5(10):13530. https://doi.org/10.1371/journal.pone. 0013530.

17. Jo BH, Hwang $\mathrm{BH}$, Cha HJ. Draft genome sequence of Hydrogenovibrio marinus $\mathrm{MH}-110$, a model organism for aerobic $\mathrm{H} 2$ metabolism. J Biotechnol. 2014;185:37-8. https://doi.org/10.1016/j.jbiotec.2014.06.009.
18. Kappler U, Davenport K, Beatson S, Lapidus A, Pan C, Han C, Montero-Calasanz MdC, Land M, Hauser L, Rohde M, G"oker M, Ivanova N, Woyke T, Klenk HP, Kyrpides NC. Complete genome sequence of the haloalkaliphilic, obligately chemolithoautotrophic thiosulfate and sulfide-oxidizing $\gamma$-proteobacterium Thioalkalimicrobium cyclicum type strain ALM 1 (DSM 14477T). Stand Genomic Sci. 2016;11(1):1-12. https:// doi.org/10.1186/s40793-016-0162-x.

19. Zhang G, Fauzi Haroon M, Zhang R, Hikmawan T, Stingl U. Draft Genome Sequences of Two Thiomicrospira Strains Isolated from the Brine-Seawater Interface of Kebrit Deep in the Red Sea. Genome Announc. 2016;4(2):00110 -16. https://doi.org/10.1128/genomeA.00110-16.

20. Jiang $L$, Lyu J, Shao Z. Sulfur metabolism of Hydrogenovibrio thermophilus strain s5 and its adaptations to deep-sea hydrothermal vent environment. Front Microbiol. 2017;8(DEC):1-12. https://doi.org/10.3389/ fmicb.2017.02513.

21. Scott KM, Williams J, Porter CMB, Russel S, Harmer TL, Paul JH, Antonen KM, Bridges MK, Camper GJ, Campla CK, Casella LG, Chase E, Conrad JW, Cruz MC, Dunlap DS, Duran L, Fahsbender EM, Goldsmith DB, Keeley RF, Kondoff MR, Kussy BI, Lane MK, Lawler S, Leigh BA, Lewis C, Lostal LM, Marking D, Mancera PA, McClenthan EC, Mclntyre EA, Mine JA, Modi S, Moore BD, Morgan WA, Nelson KM, Nguyen KN, Ogburn N, Parrino DG, Pedapudi AD, Pelham RP, Preece AM, Rampersad EA, Richards on JC, Rodgers CM, Schaffer BL, Sheridan NE, Solone MR, Staley ZR, Tabuchi M, Waide RJ, Wanjugi PW, Young S, Clum A, Daum C, Huntemann M, Ivanova N, Kyrpides N, Mikhailova N, Palaniappan K, Pillay M, Reddy TBK, Shapiro N, Stamatis D, Varghese N, Woyke T, Boden R, Freyermuth SK, Kerfeld CA. Genomes of ubiquitous marine and hypersaline Hydrogenovibrio, Thiomicrorhabdus, and Thiomicrospira spp. encode a diversity of mechanisms to sustain chemolithoautotrophy in heterogeneous environments. Environ Microbiol. 2018;00. https://doi. org/10.1111/1462-2920.14090.

22. Seemann T. Prokka: rapid prokaryotic genome annotation. Bioinformatics (Oxf, England). 20141-2. https://doi.org10.1093/bioinformatics/btu153.

23. Marchler-Bauer A, Bryant SH. CD-Search: Protein domain annotations on the fly. Nucleic Acids Res. 2004;32:327-31. https://doi.org10.1093/nar/ gkh454.

24. Kanehisa M, Sato Y, Morishima K. BlastKOALA and GhostKOALA: KEGG Tools for Functional Characterization of Genome and Metagenome Sequences. J Mol Biol. 2016;428(4):726-31. https://doi.org/10.1016/j.jmb. 2015.11.006.

25. Goris J, Konstantinidis KT, Klappenbach JA, Coenye T, Vandamme P, Tiedje JM. DNA-DNA hybridization values and their relationship to whole-genome sequence similarities. Int J Syst Evol Microbiol. 2007;57(1): 81-91. https://doi.org/10.1099/ijs.0.64483-0.

26. Bertelli C, Laird MR, Williams KP, Lau BY, Hoad G, Winsor GL, Brinkman FSL. IslandViewer 4: Expanded prediction of genomic islands for larger-scale datasets. Nucleic Acids Res. 2017;45(W1):30-5. https://doi. org/10.1093/nar/gkx343.

27. Hsiao WWL, Ung K, Aeschliman D, Bryan J, Brett Finlay B, Brinkman FSL. Evidence of a large novel gene pool associated with prokaryotic genomic Islands. PLoS Genet. 2005;1(5):540-50. https://doi. org/10.1371/journal.pgen.0010062.

28. Brazelton WJ, Baross JA. Abundant transposases encoded by the metagenome of a hydrothermal chimney biofilm. ISME J. 2009;3(12): 1420-4. https://doi.org/10.1038/ismej.2009.79.

29. Barrangou R, Fremaux C, Deveau H, Richards M, Boyaval P, Moineau S, Romero Da, Horvath P. CRISPR Provides Acquired Resistance Against Viruses in Prokaryotes. Science. 2007;315(5819):1709-12. https://doi.org/ 10.1126/science.1138140.

30. Greening C, Biswas A, Carere CR, Jackson CJ, Taylor MC, Stott MB, Cook GM, Morales SE. Genomic and metagenomic surveys of hydrogenase distribution indicate $\mathrm{H} 2$ is a widely utilised energy source for microbial growth and survival. ISME J. 2016;10(3):761-77. https://doi.org/10.1038/ ismej.2015.153.

31. Bernhard M, Friedrich $B$, Siddiqui RA. Ralstonia eutropha TF93 is blocked in tat-mediated protein export. J Bacteriol. 2000;182(3):581-8. https://doi. org/10.1128/JB.182.3.581-588.2000.

32. Shomura Y, Yoon KS, Nishihara H, Higuchi Y. Structural basis for a [4Fe3S] cluster in the oxygen-tolerant membrane-bound [NiFe]-hydrogenase. Nature. 2011;479(7372):253-6. https://doi.org/10.1038/nature10504. 
33. Yamamoto K, Hirao K, Oshima T, Aiba H, Utsumi R, Ishihama A. Functional characterization in vitro of all two-component signal transduction systems from Escherichia coli. J Biol Chem. 2005;280(2): 1448-56. https://doi.org/10.1074/jbc.M410104200.

34. Stoker K, Reijnders WN, Oltmann LF, Stouthamer AH. Initial cloning and sequencing of hydHG, an operon homologous to ntrBC and regulating the labile hydrogenase activity in Escherichia coli K-12. J Bacteriol. 1989;171(8):4448-56.

35. Lenz O, Strack A, Tran-Betcke A, Friedrich B. A hydrogen-sensing system in transcriptional regulation of hydrogenase gene expression in Alcaligenes species. J Bacteriol. 1997;179(5):1655-63. https://doi.org/10. 1128/jb.179.5.1655-1663.1997.

36. Ducluzeau AL, Ouchane S, Nitschke W. The cbb3 oxidases are an ancient innovation of the domain bacteria. Mol Biol Evol. 2008;25(6):1158-66. https://doi.org/10.1093/molbev/msn062.

37. Pitcher RS, Watmough NJ. The bacterial cytochrome cbb3 oxidases. Biochim Biophys Acta - Bioenerg. 2004;1655(1-3):388-99. https://doi.org/ 10.1016/j.bbabio.2003.09.017.

38. Adam N, Perner M. Microbially Mediated Hydrogen Cycling in Deep-Sea Hydrothermal Vents. Front Microbiol. 2018;9(November). https://doi.org/ 10.3389/fmicb.2018.02873.

39. Anantharaman K, Hausmann B, Jungbluth SP, Kantor RS, Lavy A, Warren LA, Rappé MS, Pester M, Loy A, Thomas BC, Banfield JF. Expanded diversity of microbial groups that shape the dissimilatory sulfur cycle. ISME J. 2018;12(7):1715-28. https://doi.org/10.1038/s41396-018-0078-0.

40. Distel DL, Altamia MA, Lin Z, Shipway JR, Han A, Forteza I, Antemano R, Limbaco MGJP, Tebo AG, Dechavez R, Albano J, Rosenberg G, Concepcion GP, Schmidt EW, Haygood MG. Discovery of chemoautotrophic symbiosis in the giant shipworm Kuphus polythalamia (Bivalvia: Teredinidae) extends wooden-steps theory. Proc Nat Acad Sci. 2017;114(18):3652-8. https://doi.org/10.1073/pnas.1620470114.

41. König $S, G$ ros $O$, Heiden $S E$, Hinzke $T$, Thürmer $A$, Poehlein $A$, Meyer S, Vatin M, Mbéguié-A-Mbéguié D, Tocny J, Ponnudurai R, Daniel R, Becher D, Schweder T, Markert S. Nitrogen fixation in a chemoautotrophic lucinid symbiosis. Nat Microbiol. 2016;2(October): 16193. https://doi.org/10.1038/nmicrobiol.2016.193.

42. Anderson I, Sikorski J, Zeytun A, Nolan M, Lapidus A, Lucas S, Hammon N, Deshpande S, Cheng J-F, Tapia R, Han C, Goodwin L, Pitluck S, Liolios K, Pagani I, Ivanova N, Huntemann M, Mavromatis K, Ovchinikova G, Pati A, Chen A, Palaniappan K, Land M, Hauser L, Brambilla E-M, NgatchouDjao OD, Rohde M, Tindall BJ, Göker M, Detter JC, Woyke T, Bristow J, Eisen JA, Markowitz V, Hugenholtz P, Klenk H-P, Kyrpides NC. Complete genome sequence of Nitratifractor salsuginis type strain (E9137-1T). Stand Genomic Sci. 2011;4(3):322-30. https://doi.org/10.4056/sigs.1844518.

43. Giovannelli D, Ferriera S, Johnson J, Kravitz S, Pérez-Rodríguez I, Ricci J, O'Brien C, Voordeckers JW, Bini E, Vetriani C. Draft genome sequence of Caminibacter mediatlanticus strain TB-2 T, an epsilonproteobacterium isolated from a deep-sea hydrothermal vent. Stand Genomic Sci. 2011;5(1):135-43. https://doi.org/10.4056/sigs.2094859.

44. Mori JF, Scott JJ, Hager KW, Moyer CL, Küsel K, Emerson D. Physiological and ecological implications of an iron- or hydrogen-oxidizing member of the Zetaproteobacteria, Ghiorsea bivora, gen. nov., sp. nov. ISME J. 2017;11(11):2624-36. https://doi.org/10.1038/ismej.2017.132.

45. Nakagawa S. Nitratiruptor tergarcus gen. nov., sp. nov. and Nitratifractor salsuginis gen. nov., sp. nov., nitrate-reducing chemolithoautotrophs of the -Proteobacteria isolated from a deep-sea hydrothermal system in the Mid-Okinawa Trough. Int J Syst Evol Microbiol. 2005;55(2):925-33. https:// doi.org/10.1099/ijs.0.63480-0.

46. Takai K, Nealson KH, Horikoshi K. Hydrogenimonas thermophila gen. nov., sp. nov., a novel thermophilic, hydrogen-oxidizing chemolithoautotroph within the E-Proteobacteria, isolated from a black smoker in a Central Indian Ridge hydrothermal field. Int J Syst Evol Microbiol. 2004;54(1):25-32. https://doi.org/10.1099/ijs.0.02787-0.

47. Schwartz E, Henne A, Cramm R, Eitinger T, Friedrich B, Gottschalk G. Complete Nucleotide Sequence of pHG1: A Ralstonia eutropha H16 Megaplasmid Encoding Key Enzymes of H2-based Lithoautotrophy and Anaerobiosis. J Mol Biol. 2003;332(2):369-83. https://doi.org/10.1016/ S0022-2836(03)00894-5.

48. NISHIHARA H, IGARASHI Y, KODAMA T. Hydrogenovibrio marinus gen. nov., sp. nov., a Marine Obligately Chemolithoautotrophic Hydrogen-Oxidizing Bacterium. Int J Syst Bacteriol. 1991;41(1):130-3. https://doi.org/10.1099/00207713-41-1-130.
49. Gardner PR, Gardner AM, Martin La, Salzman AL. Nitric oxide dioxygenase: an enzymic function for flavohemoglobin. Proc Natl Acad Sci U S A. 1998;95(September):10378-83. https://doi.org/10.1073/pnas.95. 18.10378.

50. Wisecaver JH, Alexander WG, King SB, Todd Hittinger C, Rokas A. Dynamic Evolution of Nitric Oxide Detoxifying Flavohemoglobins, a Family of Single-Protein Metabolic Modules in Bacteria and Eukaryotes. Mol Biol Evol. 2016;33(8):1979-87. https://doi.org/10.1093/molbev/ msw073.

51. Barco RA, Hoffman CL, Ramírez GA, Toner BM, Edwards KJ, Sylvan JB. In-situ incubation of iron-sulfur mineral reveals a diverse chemolithoautotrophic community and a new biogeochemical role for Thiomicrospira. Environ Microbiol. 2017;19(3):1322-37. https://doi.org/10. 1111/1462-2920.13666.

52. Desrosiers DC, Sun YC, Zaidi AA, Eggers CH, Cox DL, Radolf JD. The general transition metal (Tro) and Zn2+ (Znu) transporters in Treponema pallidum: Analysis of metal specificities and expression profiles. Mol Microbiol. 2007;65(1):137-52. https://doi.org/10.1111/j.1365-2958.2007. 05771.x.

53. Große C, Scherer J, Koch D, Otto M, Taudte N, Grass G. A new ferrous iron-uptake transporter, EfeU (YcdN), from Escherichia coli. Mol Microbiol. 2006;62(1):120-31. https://doi.org/10.1111/j.1365-2958.2006.05326.x.

54. Vetriani C, Chew YS, Miller SM, Yagi J, Coombs J, Lutz RA, Barkay T. Mercury adaptation among bacteria from a deep-sea hydrothermal vent. Appl Environ Microbiol. 2005;71(1):220-6. https://doi.org/10.1128/AEM. 71.1.220-226.2005.

55. Freedman Z, Zhu C, Barkay T. Mercury resistance and mercuric reductase activities and expression among chemotrophic thermophilic aquificae. Appl Environ Microbiol. 2012;78(18):6568-75. https://doi.org/10.1128/ AEM.01060-12.

56. Romero H, Zhang Y, Gladyshev VN, Salinas G. Evolution of selenium utilization traits,. Genome Biol. 2005;6(8):66. https://doi.org/10.1186/gb2005-6-8-r66

57. Su D, Ojo TT, Söll D, Hohn MJ. Selenomodification of tRNA in archaea requires a bipartite rhodanese enzyme. FEBS Lett. 2012;586(6):717-21. https://doi.org/10.1016/j.febslet.2012.01.024.

58. Wilde E. Untersuchungen über Wachstum und Speicherstoffsynthese von Hydrogenomonas. Arch Mikrobiol. 1962;43(2):109-137. https://doi.org/ 10.1007/BF00406429.

59. Dobrinski KP, Longo DL, Scott KM. The carbon-concentrating mechanism of the hydrothermal vent chemolithoautotroph Thiomicrospira crunogena. J Bacteriol. 2005;187(16):5761-6. https://doi. org/10.1128/JB.187.16.5761-5766.2005.

60. Böhnke S, Perner M. A function-based screen for seeking RubisCO active clones from metagenomes: Novel enzymes influencing RubisCO activity. ISME J. 2015. https://doi.org/10.1038/ismej.2014.163.

61. Andrews S. FastQC: a quality control tool for high throughput sequence data. 2010. http://www.bioinformatics.babraham.ac.uk/projects/fastqc.

62. Koren S, Walenz BP, Berlin K, Miller JR, Bergman NH, Phillippy AM. Canu: scalable and accurate long-read assembly via adaptive k-mer weighting and repeat separation. Genome Res. 2017;27(5):722-36. https://doi.org/ 10.1101/gr.215087.116.

63. Hunt M, Silva ND, Otto TD, Parkhill J, Keane JA, Harris SR. Circlator: Automated circularization of genome assemblies using long sequencing reads. Genome Biol. 2015;16(1):1-10. https://doi.org/10.1186/s13059015-0849-0.

64. Li H. Aligning sequence reads, clone sequences and assembly contigs with BWA-MEM. ArXix. 2013. http://arxiv.org/abs/1303.3997. https://doi. org/arXiv:1303.3997. http://arxiv.org/abs/1303.3997.

65. Li H. A statistical framework for SNP calling, mutation discovery, association mapping and population genetical parameter estimation from sequencing data. Bioinformatics. 2011;27(21):2987-93. https://doi. org/10.1093/bioinformatics/btr509.

66. Walker BJ, Abeel T, Shea T, Priest M, Abouelliel A, Sakthikumar S, Cuomo CA, Zeng Q, Wortman J, Young SK, Earl AM. Pilon: An integrated tool for comprehensive microbial variant detection and genome assembly improvement. PLOS ONE. 2014;9(11). https://doi.org/10.1371/ journal.pone.0112963.

67. Camacho C, Coulouris G, Avagyan V, Ma N, Papadopoulos J, Bealer K, Madden TL. BLAST+: Architecture and applications. BMC Bioinformatics. 2009;10:1-9. https://doi.org/10.1186/1471-2105-10-421. 
68. O'Leary NA, Wright MW, Brister JR, Ciufo S, Haddad D, McVeigh R, Rajput B, Robbertse B, Smith-White B, Ako-Adjei D, Astashyn A, Badretdin A, Bao Y, Blinkova O, Brover V, Chetvernin V, Choi J, Cox E, Ermolaeva O, Farrell CM, Goldfarb T, Gupta T, Haft D, Hatcher E, Hlavina W, Joardar VS, Kodali VK, Li W, Maglott D, Masterson P, McGarvey KM, Murphy MR, O'Neill K, Pujar S, Rangwala SH, Rausch D, Riddick LD, Schoch C, Shkeda A, Storz SS, Sun H, Thibaud-Nissen F, Tolstoy I, Tully RE, Vatsan AR, Wallin C, Webb D, Wu W, Landrum MJ, Kimchi A, Tatusova T, DiCuccio M, Kitts P, Murphy TD, Pruitt KD. Reference sequence (RefSeq) database at NCBI: Current status, taxonomic expansion, and functional annotation. Nucleic Acids Res. 2016;44(D1): 733-45. https://doi.org/10.1093/nar/gkv1189.

69. Richter M, Rossello-Mora R. Shifting the genomic gold standard for the prokaryotic species definition. Proc Natl Acad Sci. 2009;106(45):19126-31. https://doi.org/10.1073/pnas.0906412106.

70. Hudson CM, Lau BY, Williams KP. Islander: A database of precisely mapped genomic islands in tRNA and tmRNA genes. Nucleic Acids Res. 2015;43(D1):48-53. https://doi.org/10.1093/nar/gku1072.

71. Krumsiek J, Arnold R, Rattei T. Gepard: A rapid and sensitive tool for creating dotplots on genome scale. Bioinformatics. 2007;23(8):1026-8. https://doi.org/10.1093/bioinformatics/btm039.

72. Darling AE, Mau B, Perna NT. progressiveMauve: Multiple Genome Alignment with Gene Gain, Loss and Rearrangement. PLOS ONE. 2010;5(6):11147. https://doi.org/10.1371/journal.pone.0011147.

73. Kanehisa M, Goto S, Sato Y, Kawashima M, Furumichi M, Tanabe M. Data, information, knowledge and principle: Back to metabolism in KEGG. Nucleic Acids Res. 2014;42(D1):199-205. https://doi.org/10.1093/nar/ gkt1076.

74. Galperin MY, Makarova KS, Wolf YI, Koonin EV. Expanded Microbial genome coverage and improved protein family annotation in the COG database. Nucleic Acids Res. 2015;43(D1):261-9. https://doi.org/10.1093/ nar/gku1223.

75. Krzywinski M, Schein J, Birol I, Connors J, Gascoyne R, Horsman D, Jones SJ, Marra MA. Circos: an information aesthetic for comparative genomics. Genome Res. 2009;19(9):1639-45. https://doi.org/10.1101/gr.092759.109.

76. El-Gebali S, Mistry J, Bateman A, Eddy SR, Luciani A, Potter SC, Qureshi M, Richardson LJ, Salazar GA, Smart A, Sonnhammer ELL, Hirsh L, Paladin L, Piovesan D, Tosatto SCE, Finn RD. The Pfam protein families database in 2019. Nucleic Acids Res. 2018;47(October 2018):427-32. https://doi.org/10.1093/nar/gky995.

77. Chen I-MA, Chu K, Palaniappan K, Pillay M, Ratner A, Huang J, Huntemann M, Varghese N, White JR, Seshadri R, Smirnova T, Kirton E, Jungbluth SP, Woyke T, Eloe-Fadrosh EA, Ivanova NN, Kyrpides NC. IMG/M v.5.0: an integrated data management and comparative analysis system for microbial genomes and microbiomes. Nucleic Acids Res. 2018;47(October 2018):666-77. https://doi.org/10.1093/nar/gky901.

78. Keseler IM, Mackie A, Santos-Zavaleta A, Billington R,

Bonavides-Martínez C, Caspi R, Fulcher C, Gama-Castro S, Kothari A, Krummenacker M, Latendresse M, Muñiz-Rascado L, Ong Q, Paley S, Peralta-Gil M, Subhraveti P, Velázquez-Ramírez DA, Weaver D, Collado-Vides J, Paulsen I, Karp PD. The EcoCyc database: Reflecting new knowledge about Escherichia coli K-12. Nucleic Acids Res. 2017;45(D1): 543-50. https://doi.org/10.1093/nar/gkw1003.

79. Edgar RC. MUSCLE: Multiple sequence alignment with high accuracy and high throughput. Nucleic Acids Res. 2004;32(5):1792-7. https://doi.org/ 10.1093/nar/gkh340.

80. Chakravorty S, Helb D, Burday M, Connell N, Alland D. A detailed analysis of $16 \mathrm{~S}$ ribosomal RNA gene segments for the diagnosis of pathogenic bacteria. J Microbiol Methods. 2007;69(2):330-9. https://doi. org/10.1016/j.mimet.2007.02.005.

Ready to submit your research? Choose BMC and benefit from:

- fast, convenient online submission

- thorough peer review by experienced researchers in your field

- rapid publication on acceptance

- support for research data, including large and complex data types

- gold Open Access which fosters wider collaboration and increased citations

- maximum visibility for your research: over $100 \mathrm{M}$ website views per year

At BMC, research is always in progress.

Learn more biomedcentral.com/submissions 